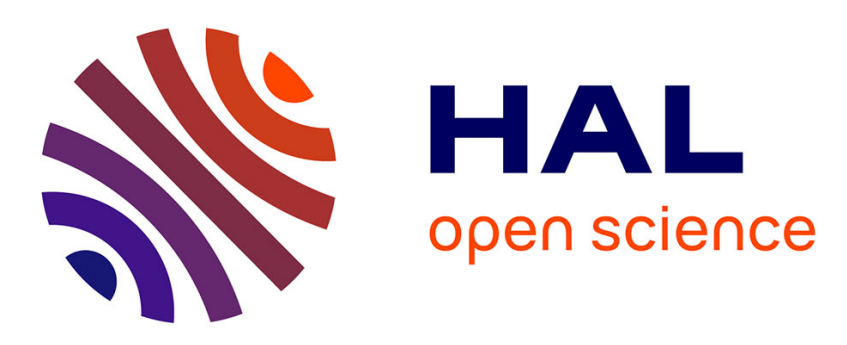

\title{
Pulsed electric fields induce extracellular matrix remodeling through MMPs activation and decreased collagen production
}

Sara Gouarderes, Camille Ober, Layal Doumard, Jany Dandurand, Patricia Vicendo, Isabelle Fourquaux, Alexander Golberg, Valérie Samouillan, Laure Gibot

\section{To cite this version:}

Sara Gouarderes, Camille Ober, Layal Doumard, Jany Dandurand, Patricia Vicendo, et al.. Pulsed electric fields induce extracellular matrix remodeling through MMPs activation and decreased collagen production. Journal of Investigative Dermatology, 2022, 142 (5), pp.1326-1337.e9. 10.1016/j.jid.2021.09.025 . hal-03428701

\section{HAL Id: hal-03428701 https://hal.science/hal-03428701}

Submitted on 15 Nov 2021

HAL is a multi-disciplinary open access archive for the deposit and dissemination of scientific research documents, whether they are published or not. The documents may come from teaching and research institutions in France or abroad, or from public or private research centers.
L'archive ouverte pluridisciplinaire HAL, est destinée au dépôt et à la diffusion de documents scientifiques de niveau recherche, publiés ou non, émanant des établissements d'enseignement et de recherche français ou étrangers, des laboratoires publics ou privés. 
Pulsed electric fields induce extracellular matrix remodeling through MMPs activation and decreased collagen production

Sara Gouarderes ${ }^{1}$, Camille Ober ${ }^{2}$, Layal Doumard ${ }^{1}$, Jany Dandurand ${ }^{2}$, Patricia Vicendo ${ }^{1}$, Isabelle Fourquaux ${ }^{3}$, Alexander Golberg $^{4}$, Valérie Samouillan ${ }^{2}$, Laure Gibot ${ }^{1}$

${ }^{1}$ Laboratoire des IMRCP, Université de Toulouse, CNRS UMR 5623, Université Toulouse III - Paul Sabatier, France.

${ }^{2}$ CIRIMAT UMR 5085, Université de Toulouse, Université Toulouse III - Paul Sabatier, France

${ }^{3}$ Centre de Microscopie Électronique Appliquée à la Biologie, CMEAB, 133 route de Narbonne, 31062 Toulouse, France

${ }^{4}$ Porter School of Environment and Earth Sciences Studies, Tel Aviv University, Tel Aviv, Israel

SHORT TITLE Electroporation to remodel matrix

CORRESPONDING AUTHOR Dr Laure Gibot, Laboratoire des IMRCP, Université Toulouse III - Paul Sabatier, 118 route de Narbonne, 31066 Toulouse, France. +33561556272 gibot@chimie.ups-tlse.fr

KEYWORDS reversible electroporation, electrochemotherapy (ECT), gene electrotransfer (GET), metalloproteinases (MMPs), skin, tissue engineering

ABBREVIATIONS ECM: extracellular matrix; LP: long pulses protocol; MMPs: metalloproteinases; PEFs: pulsed electric fields; SP: short pulses protocol; ROS: reactive oxygen species 


\begin{abstract}
Impairment of extracellular matrix (ECM) remodeling is observed in the tumor microenvironment or fibrosis and results in excessive collagen production and/or decreased degradation by metalloproteinases MMPs. Thanks to their local application and transient effects, physical stimuli appear as attractive tools to remodel ECM. We assessed the potential of pulsed electric field technology, classically applied to drug delivery, to induce collagen remodeling at the tissue scale. A sophisticated in vitro tissue-engineered human dermal substitute was used to demonstrate that microsecond and millisecond pulsed electric fields induced 1) a rapid modulation (4h after electrostimulation) of mRNA's genes composing the matrisome, particularly a down-regulation of pro-collagens and ECM maturation's enzymes such as transglutaminase TG2 and LOX-like; 2) a transient decrease in pro-collagens production and hydroxyproline tissue content within a week after electrostimulation; 3) a long-lasting ROS-dependent over-activation of MMPs for at least 48h and 4) a downregulation of TGF- $\beta$. These observations underpin that pulsed electric fields, a technology already approved for clinical use combined with anti-cancer agents, are particularly promising to provide local and effective treatment of abnormal ECM.
\end{abstract}

INTRODUCTION. The extracellular matrix (ECM) is a dynamic and complex mesh of structural proteins and carbohydrates that are essential for tissue development, structure, and functionality (Frantz et al. 2010). Impairment in its regulation, composition, biophysical properties and remodeling is observed in diseases such as cancers or fibrosis (Winkler et al. 2020). ECM components and the proteins that regulate ECM remodeling appear as promising therapeutic targets for human healthcare (Ivey et al. 2016). Physical strategies such as radiotherapy, hyperthermia, photodynamic therapy or emerging ones (plasma, sonoporation) appear to be a relevant strategic solution to induce ECM remodeling (Gouarderes et al. 
2020b). Their local effect and space-time control application resonate with the ongoing quest to alleviate patients' adverse side effects from systemic pharmacological approaches.

In this study, we applied external pulsed electric fields (PEFs) that increase the cell membrane permeability, a phenomenon known as electroporation, presenting a wide variety of biomedical applications (Geboers et al. 2020). Electroporation can be either reversible or irreversible. While irreversible electroporation (IRE) and partial IRE lead to cell death and preservation of the structural integrity of surrounding tissue (Davalos et al. 2005; Golberg et al. 2016; Golberg et al. 2018), on the contrary, reversible electroporation transiently increase membrane permeability, enhancing concomitant delivery of therapeutics in drug delivery strategy, while preserving cell viability. In our work, we focused on reversible electroporation and applied similar electrical conditions to those applied in clinics for drug delivery. Thus, two distinct calibrated electric protocols already used in routine in human and veterinarian clinics for drug delivery to cure superficial and deep tumors were applied (Nuccitelli 2019; Yarmush et al. 2014). They consist of millisecond length "long pulses protocol" (LP) which is used for nucleic acids delivery in DNA vaccination gene therapy, and microsecond length "short pulses protocol" (SP) used for anti-tumor drug delivery in electrochemotherapy (Marty et al. 2006; Gehl et al. 2018). Our strategy lay on applying solely physical electrical stimuli, without the addition of any drugs, to modulate cell behavior. These calibrated electric parameters were applied to a sophisticated in vitro tissue-engineered human dermal substitute, produced through the self-assembly approach in which cells produce their own extracellular matrix (Athanasiou et al. 2013). Thus, the final tissue substitutes are rich in endogenous ECM proteins, as demonstrated by proteomic analyses (Magnan et al. 2018), demonstrating its complex composition and similarity to the native dermis.

Our findings indicate that applying a calibrated train of electric pulses as a purely physical stimulus tends to be a relevant therapeutic tool with a broad potential that can extend far 
beyond its actual clinical application in electrochemotherapy. A good understanding of the cell mechanisms induced by the electric field itself (no need for external molecules addition) will increase its applicability in a context where ECM is abnormal such as in fibrosis.

\section{RESULTS AND DISCUSSION}

\section{Human dermal substitutes present a unique biological architecture rich in collagens.}

Nowadays, researchers have the most benefit of hindsight with PEFs treatment of skin cancers. To demonstrate the high potential of PEFs in ECM remodeling, we turned to a model of human dermis substitute we have engineered. Scanning electron microscopy showed a polarization of the tissue model, with more cells on its top (culture medium side) and more ECM fibers on its bottom (Petri side) (Fig1A, B). Transmission electron microscopy of a whole transversal section confirmed this vertical gradient of cells and ECM (Fig1C). A zoom performed on the ECM part allowed to detect the characteristic banding pattern of collagens fibrils (Fig1D). Of note, fibril-forming collagens types I, III, and V, characterized by their ability to assemble into highly orientated supramolecular fibrils, are the main components of the human dermal extracellular matrix (Gelse 2003) and of the human dermal substitutes as assessed by proteomics (Magnan et al. 2018). This result correlated with the second-harmonic generation (SHG) signal, detected by two-photon microscopy, which confirms the proper organization of these fibrillar collagens within our tissue model (Fig1E). Fourier Transform Infrared-Attenuated Total Reflectance (FTIR-ATR) (Sanden et al. 2019) corroborated the polarization of the tissue model (Fig1F, FigS1, Table S1). 

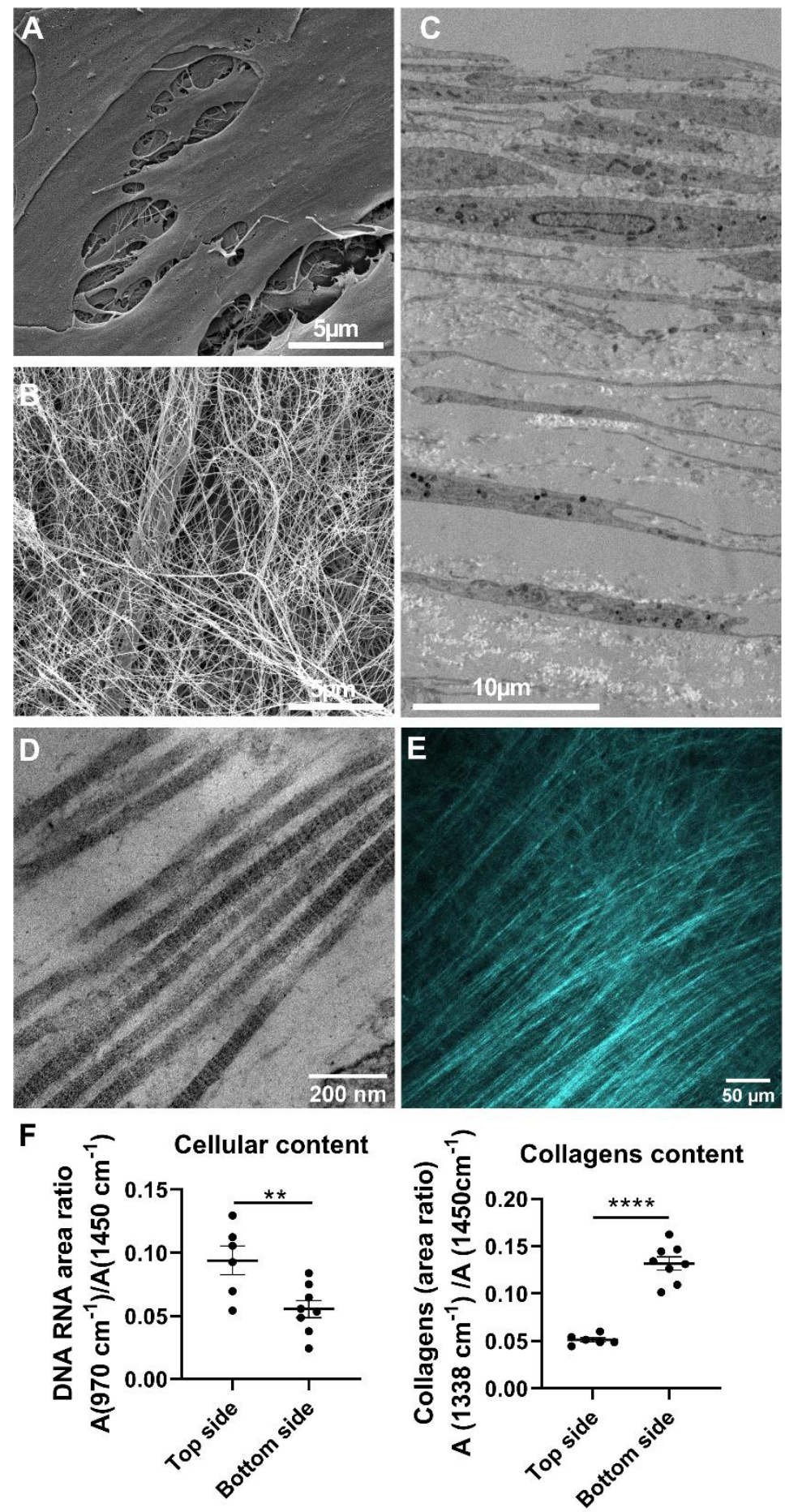

Figure 1. Human tissue-engineered 3D dermal substitutes are rich in collagens and present a top/bottom polarisation. A. Top surface (cell culture medium side) of dermal cell sheet observed by scanning electron microscopy (SEM). B. Bottom surface (Petri side) of dermal cell sheet observed by SEM. C. Transversal section of dermal substitute observed by transmission electron microscopy (TEM). D. Striated collagens fibrils observed by TEM. E. Second Harmonic Generation (SHG, in cyan) signal detected in the top view of substitute by two-photon microscopy. F. Nucleic acids and collagens repartition between the medium side (top side) and Petri side (bottom side) measured by FTIR-ATR. $\mathrm{n}>6$. 
PEFs induce a differential expression of matrisome's genes. Mean FTIR spectra pointed out that electrostimulation did not cause significant alteration of the global spectral signature of the different biological components but changes in bands intensities (FigS2). Interestingly, a focus on RNA $990 \mathrm{~cm}^{-1}$ band (Fig2A) evidenced a significant transient increase in RNA content of each side of the substitute $24 \mathrm{~h}$ after electrostimulation. Transcriptomic analysis of differentially expressed genes in the whole tissue was led $4 \mathrm{~h}$ after electrostimulation, within a time frame close to the stress, in order to not lose the dynamics following the application of PEFs. Results showed that among the 20,000 genes analyzed, 606 genes were differentially ( \pm 2 fold-changes and $p$-value $\mathrm{p}<0.01$ ) expressed $4 \mathrm{~h}$ after long pulses (LP) protocol (350 upregulated and 256 down-regulated) and 351 after short pulses SP protocol (258 up-regulated and 93 down-regulated) (Fig2B). All the genes modulated by SP protocol were also regulated in LP protocol, meaning that common pathways are activated independently of the pulse protocol applied. Gene ontology analysis was led using GOrilla tool (Eden et al. 2009) in order to visualize the most significantly enriched biological processes following electrostimulation (table S2). It appeared that metabolic pathway processes at large were mainly affected. In the context of our study, we focused on genes involved in the composition of the matrisome defined as the list of all the genes coding for proteins entering in the composition of matrices, grouping the "core matrisome" and "matrisome associated proteins" (Hynes and Naba 2012; Naba et al. 2016). Exhaustive transcriptomic results are dispatched in tables S3 (core matrisome) and S4 (matrisome-associated proteins). Presented volcano plots indicated that most of the genes impacted by PEFs were assigned to matrisome-associated proteins sub-panel and consisted principally in secreted proteins such as growth factors, regulatory factors such as metalloproteases MMPs and their inhibitors, and enzymes responsible for ECM cross-linking (Fig2C). Previous in vitro studies confirmed the ability of 
PEFs to favor growth factors and the release of cytokines from different cell types at protein level (Garner et al. 2020; Gouarderes et al. 2020a).
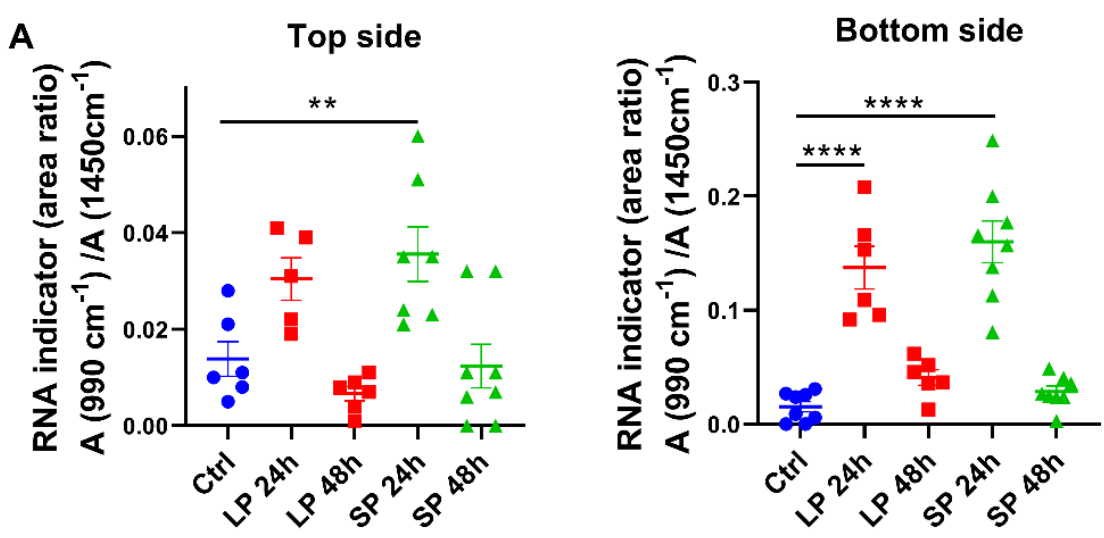

B
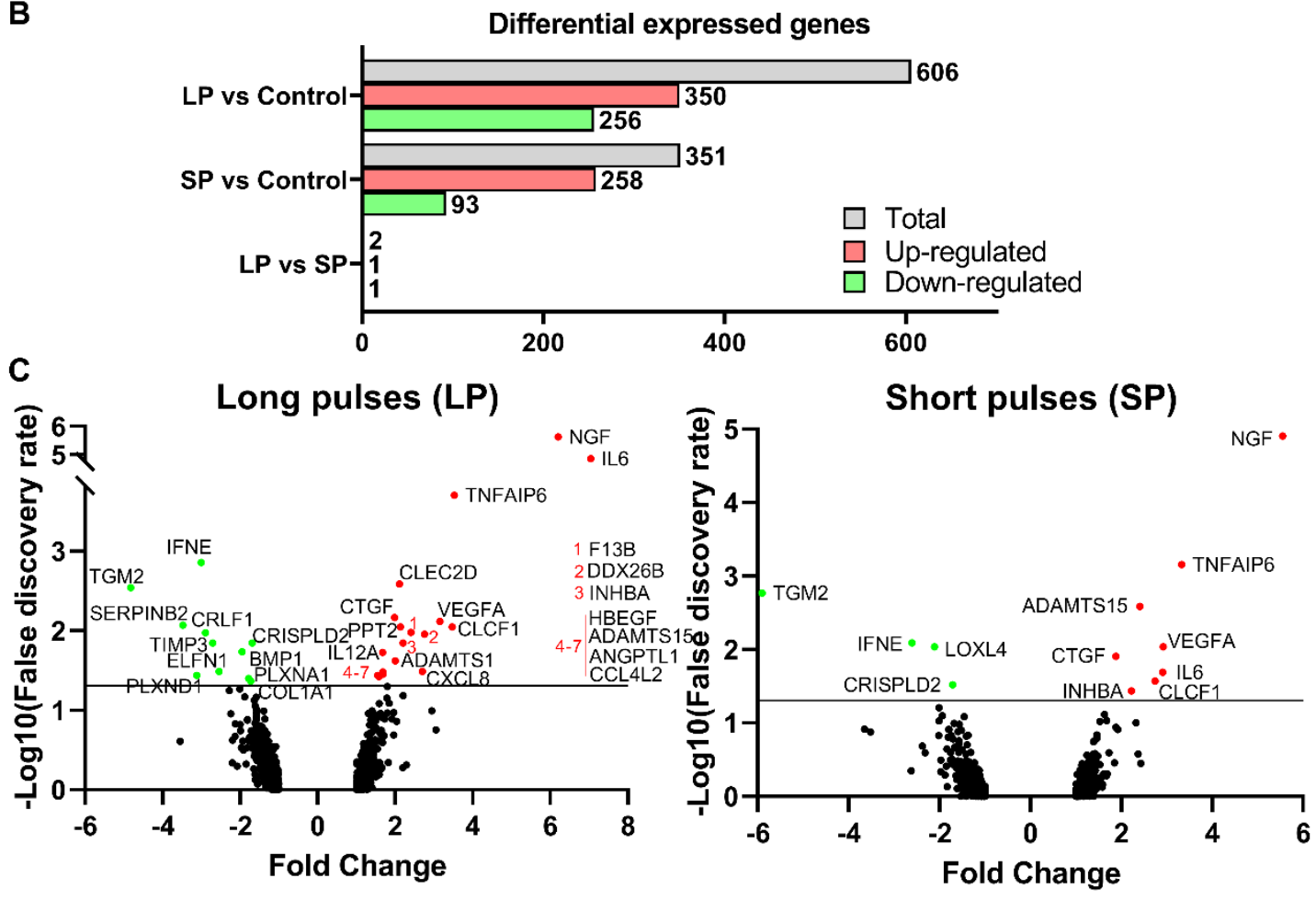

Figure 2. RNA content is modulated in dermal substitutes after electrostimulation. A. RNA indicators in the top (enriched in cells) and bottom (enriched in ECM) sides of the dermal substitute measured by FTIR-ATR $24 \mathrm{~h}$ and $48 \mathrm{~h}$ after electrostimulation. $\mathrm{n}>6$. Control condition ( $\mathrm{Ctrl} \bullet$ ), long pulses (LP $\square$ ), and short pulses (SP $\Delta$ ) protocols. B. Differentially expressed genes $4 \mathrm{~h}$ after electrostimulation in control (Ctrl) condition, long pulses (LP) and short pulses (SP) protocols among the 20,000 genes analyzed by transcriptomic analysis using Clariom S Affymetrix array. $n=4$. C. Volcano plots showing the significant impact on differentially expressed matrisome's genes $4 \mathrm{~h}$ after pulsed electric field stimulation with LP, and SP protocols. ADAMTS1: ADAM metallopeptidase with thrombospondin type 1 motif 1; ADAMTS15: ADAM metallopeptidase with thrombospondin type 1 motif 15; ANGPTL1: angiopoietin like 1; BMP1: bone morphogenetic protein 1; CCL4L2: chemokine (C-C motif) ligand 4-like 2; CLCF1: cardiotrophin-like cytokine factor 1; CLEC2D: C-type lectin domain 
family 2, member D; COL1A1: collagen 1A1; CRISPLD2: cysteine-rich secretory protein LCCL domain containing 2; CRLF1: cytokine receptor-like factor 1; CTGF: connective tissue growth factor; CXCL8: chemokine (C-X-C motif) ligand 8; DDX26B: (Asp-Glu-AlaAsp/His) box polypeptide 26B; ELFN1: extracellular leucine-rich repeat and fibronectin type III domain containing 1; F13B: coagulation factor XIII, B polypeptide; HBEGF: heparinbinding EGF-like growth factor; IFNE: interferon epsilon; IL12A: interleukin 12A; IL6: interleukin 6; INHBA: inhibin beta A; LOXL4: lysyl oxidase-like 4; NGF: nerve growth factor; PLXNA1: plexin A1; PLXND1: plexin D1; PPT2: palmitoyl-protein thioesterase 2; SERPINB2: serpin peptidase inhibitor member 2; TGM2: transglutaminase 2; TIMP3: TIMP metallopeptidase inhibitor 3; TNFAIP6: tumor necrosis factor, alpha-induced protein 6; VEGFA: vascular endothelial growth factor A.

PEFs induce a transient decrease in collagens production. mRNA modulation of the whole collagen family members $4 \mathrm{~h}$ after the dermal tissue has been electrostimulated indicated a general trend towards a decrease in the expression of collagens (Table S3 and FigS3A). FTIRATR analyses of dermal substitutes $24 \mathrm{~h}$ and $48 \mathrm{~h}$ after electrostimulation indicated that the collagens $1338 \mathrm{~cm}^{-1}$ band was not altered on the top side, rich in cells, but decreased in the bottom side, rich in ECM, solely for SP protocol conditions (Fig3A). Because FTIR-ATR is a superficial probe (up to $3.6 \mu \mathrm{m}$ depth), we performed differential scanning calorimetry (DSC) analyses in order to evaluate collagens integrity in the whole tissue (FigS4). No significant differences were observed for denaturation enthalpy $\Delta \mathrm{H}_{\mathrm{d}}$ and denaturation temperature $\mathrm{T}_{\mathrm{MID}}$ after electrostimulation, indicating no major variation in collagens integrity after PEFs application. In parallel, we performed a whole tissue hydroxyproline quantification to estimate global collagen content, $48 \mathrm{~h}$, one week, and four weeks after the electrostimulation (Fig3B). Regardless of the electric protocol applied, a significant decrease ranging from 35\% to $50 \%$ in tissue collagen's content was observed 1 week after electrostimulation. We verified that this decrease in hydroxyproline content one week after electrostimulation was not due to a decrease in the number of living cells capable of synthesizing collagens. No statistical difference between the control condition $(110,000$ cells $\pm 10,300)$ and the LP $(116,000$ cells \pm $8,600)$ and SP $(130,000$ cells $\pm 6,600)$ conditions was observed. This decrease in tissue 
collagen's content was totally reversed after a long-term culture ( 4 weeks), demonstrating the character transient of the electrostimulation effects in an irrefutable way. To determine if this drop in global collagens content arises from a decrease in collagens production, the abundance of major dermal collagen (Ricard-Blum 2011), namely collagen I, was quantified in the supernatant (Fig3C). The analyses showed a significant decrease in pro-collagen I $\alpha 1$ abundance in the supernatant of about $25 \%$ compared to the control condition as soon as $24 \mathrm{~h}$ consecutively to electrostimulation, which lasted at least $48 \mathrm{~h}$.
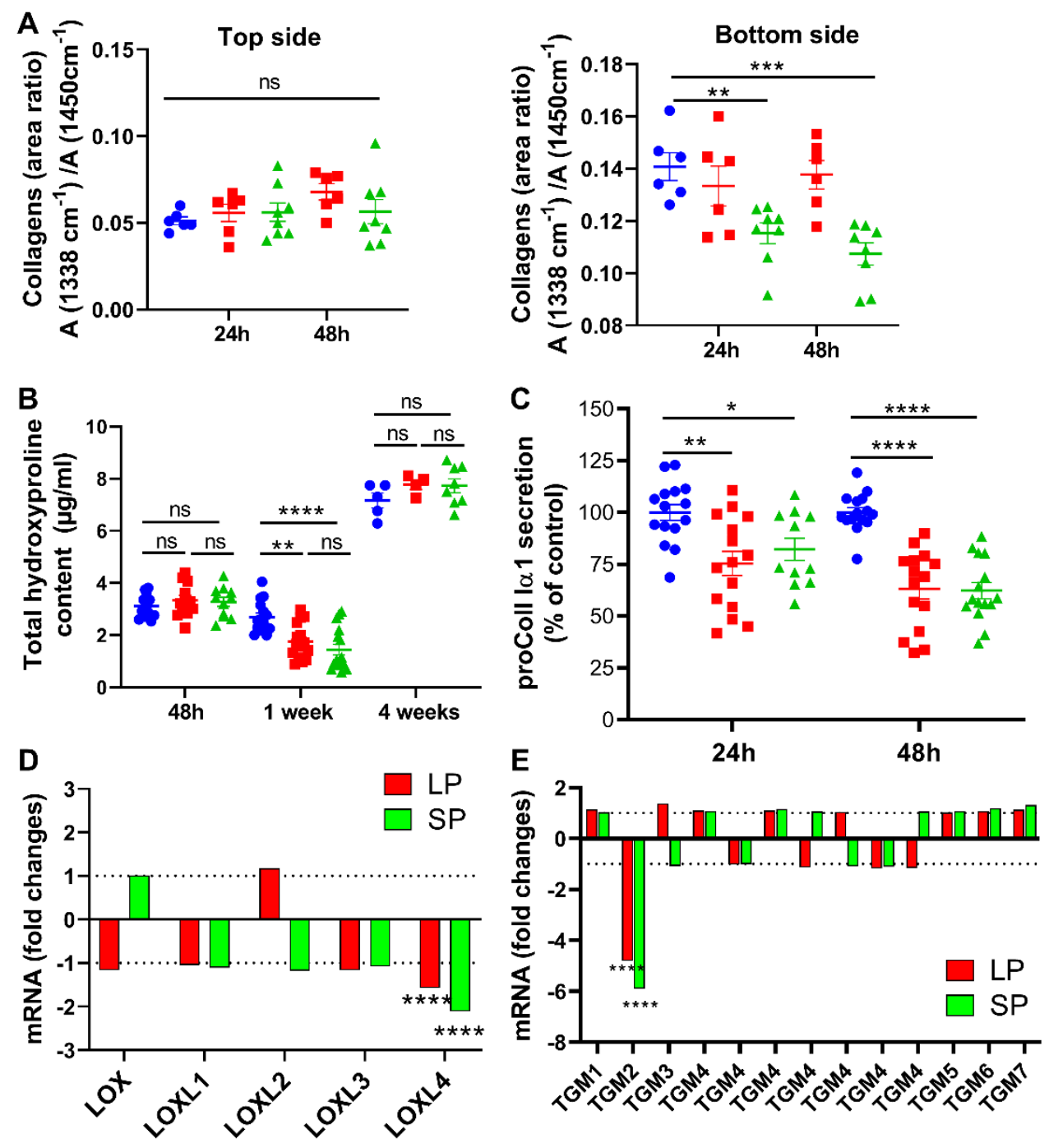

Figure 3. Collagens content transiently decreased in dermal substitute after electrostimulation. A. Collagens indicator in the top (enriched in cells) and bottom (enriched in ECM) sides of the dermal substitute measured by FTIR-ATR $24 \mathrm{~h}$ and $48 \mathrm{~h}$ after electrostimulation. B. Hydroxyproline content in the whole dermal substitute measured over 
the time after electrostimulation. C. Dosage by ELISA of pro-collagen I $\alpha 1$ in supernatants. D. Modulation of lysyl-oxidases (LOX) family's mRNA $4 \mathrm{~h}$ after electrostimulation. E. Modulation of transglutaminase (TGM) family's mRNA 4h after electrostimulation. Control condition $(\mathrm{Ctrl} \bullet$ ), long pulses (LP $\square$ ), and short pulses (SP $\triangle$ ) protocols.

During their maturation phase, collagen fibrils and other ECM components are strengthened by covalent cross-linking by lysyl oxidases (LOXs), lysyl hydroxylases, and tissue transglutaminases (TGs) (Griffin et al. 2002; Gelse 2003; Scott et al. 2012). In our experiments, analyses of LOXs mRNA family indicated a significant decrease for LOXL4 mRNA (Fig3D), and a major down-regulation (by -5 and -6 -fold changes for LP and SP, respectively) of TG2 expression in transglutaminases mRNA family (Fig3E). TG2 is the most widely distributed and expressed member of the transglutaminase enzyme family (Collighan and Griffin 2009). Our results on LOX and TG mRNA down-regulation are significant but would deserve further investigation, by quantifying not only the protein level of these enzymes (ELISA) but also their activity (functional assays). A better definition of the effect of PEFs on the effective modulation of their activities, whose deregulation is implicated in many diseases (Trackman 2016; Szondy et al. 2017), would allow envisaging new therapeutic applications for this physical technology.

PEFs induce sustained activation of MMPs without overexpression of the proteins. In order to understand the origin of collagen decrease after electrostimulation, we analyzed the mRNA modulation of the whole MMPs family members (FigS3B). 4h after electrostimulation, mRNAs of MMP-1 (-3.5-fold changes), and to a lesser extent MMP-2, -14, -16 were significantly down-regulated while MMP-19 mRNA was up-regulated. We then moved to the protein level, to quantify the main major cutaneous MMPs by ELISA, namely MMP-1, -2, -3, -9 (Amălinei et al. 2007; Kähäri and Saarialho-Kere 1997) (Fig4A). ELISA 
analyses showed that MMP-1 and MMP-2 protein expression slightly and transiently decreased in the 6 first hours after electrostimulation, while no difference in protein quantity was observed for MMP-3 over $48 \mathrm{~h}$ after treatment. By contrast, MMP-9 was significantly higher in abundance at both $24 \mathrm{~h}$ and $48 \mathrm{~h}$ after LP protocol was applied, but not after SP protocol. 

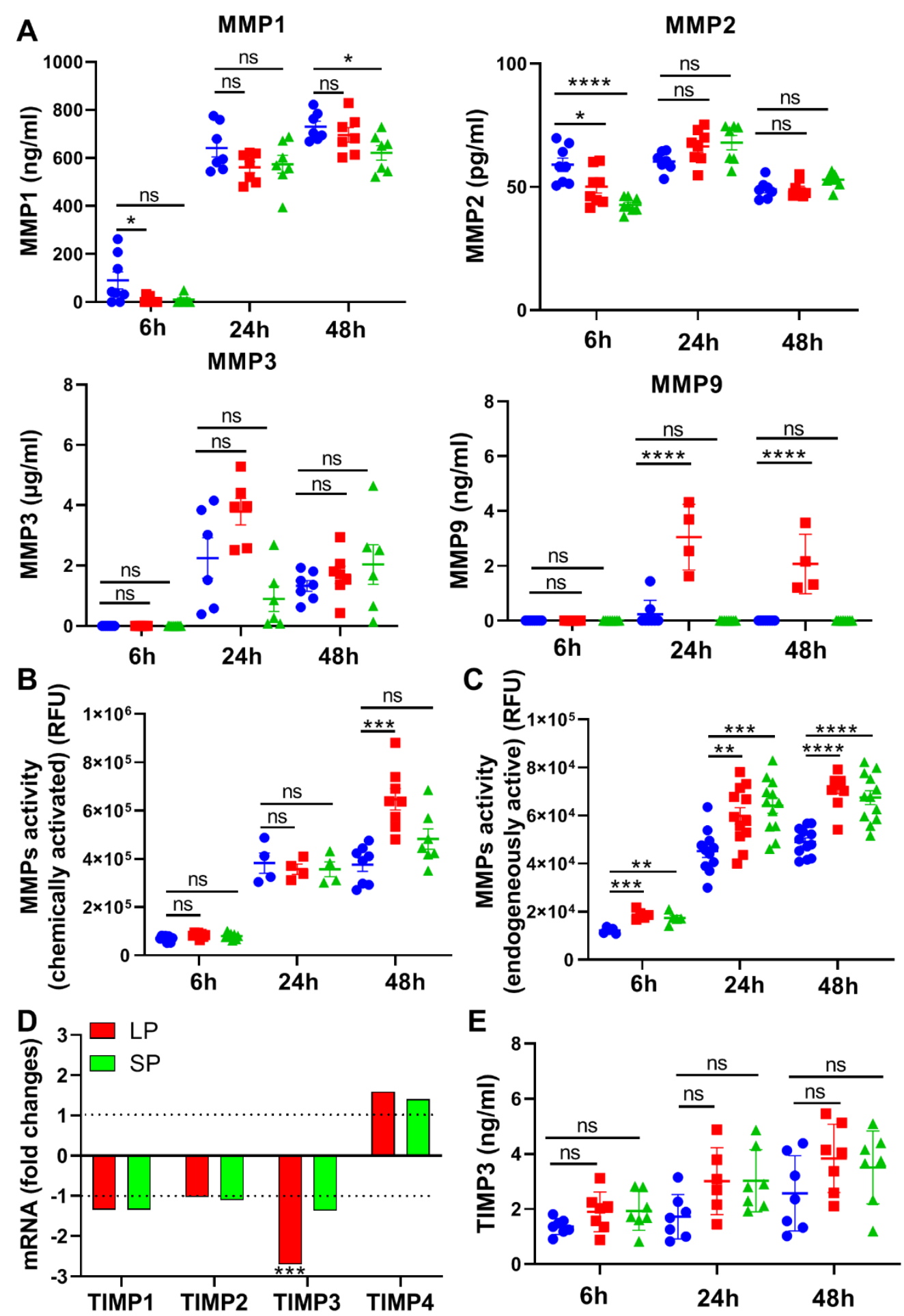

Figure 4. MMPs activity but not expression is increased after electrostimulation. A. Expression of MMP-1, -2, -3, and -9, quantified in the supernatant by ELISA. B. Global MMPs activity quantified by fluorimetry after chemical activation of all pro-MMPs present in the supernatant. C. Quantification by fluorimetry of endogenously active MMPs in the supernatant. D. Modulation of TIMPs family mRNA 4h after electrostimulation. E. TIMP-3 expression quantified in the supernatant by ELISA. Control condition ( $\mathrm{Ctrl} \bullet)$, long pulses (LP $\square$ ), and short pulses (SP $\Delta$ ) protocols. 
The cleavage of inactive zymogen (pro-MMPs) is a key step for their proteinase functions. In order to quantify the global amount of MMPs in the supernatant, we took advantage of the ability of organomercurial compounds to in vitro cleave pro-MMPs into their active form (Fig4B). Interestingly, no difference of global signal was observed $6 \mathrm{~h}$ and $24 \mathrm{~h}$ after electrostimulation, meaning that the quantity of MMPs in the supernatant is similar between control and electrostimulated conditions. However, a clear overexpression of global MMPs was noted in LP protocol $48 \mathrm{~h}$ post-electrostimulation, which follows the same trends observed previously in the ELISA results for MMP-9 (Fig4A). To go further and be more realistic of the process involved in our experimental conditions, the activity of the solely endogenously active MMPs was quantified, reflecting the actual activity rate of MMPs in the model (Fig4C). A clear increase in MMPs activity was observed as soon as 6 hours after electrostimulation and maintained for at least 48 hours. Since this increase was not due to an overproduction of MMPs as quantified at the protein level (Fig4A and B), we hypothesized that its endogenous inhibitors, the TIMPs family, were down-regulated. The transcriptomic analysis of mRNA modulation of the TIMPs family members $4 \mathrm{~h}$ after electrostimulation indicated that only TIMP3 was statistically down-regulated in LP protocol (Fig4D), an observation not confirmed at protein levels by ELISA (Fig4E).

Pharmacological MMPs' inhibitor partly restores collagens content. In order to estimate the degree of causality between MMP over-activity and the decrease in collagens content observed in tissues after the application of both LP and SP protocols, we added a broadspectrum pharmacological inhibitor, namely GM6001 or Ilomastat, to the cultures. As expected, after $48 \mathrm{~h}$ of culture, MMPs activity was non-significantly different between conditions in the presence of the inhibitor (Fig5A). Moreover, total hydroxyproline content in 
tissues one week after electrostimulation was statistically restored when MMPs activity was inhibited with GM6001 (Fig5B). While inhibition of MMPs activity after SP protocol clearly normalizes whole tissue collagen content, it was less efficient after LP protocol. FTIR-ATR analyses performed on the bottom side (richer in ECM) of the dermal substitutes $24 \mathrm{~h}$ and $48 \mathrm{~h}$ after electrostimulation confirmed that collagens content was restored in the presence of GM6001 after SP protocol, while no effect was detectable for LP protocol (Fig5C). ECM remodeling is a subtle balance between synthesis/maturation/degradation which seems more complex for LP than SP protocol. Since pulses last longer in LP protocol, it seems reasonable to hypothesize that cells within the tissue are more affected and develop a more complex response to this stress. A key element to support this hypothesis is the higher number of modulated genes in the LP protocol compared to the SP protocols (606 versus 351 respectively) as determined by transcriptomic analyses. 

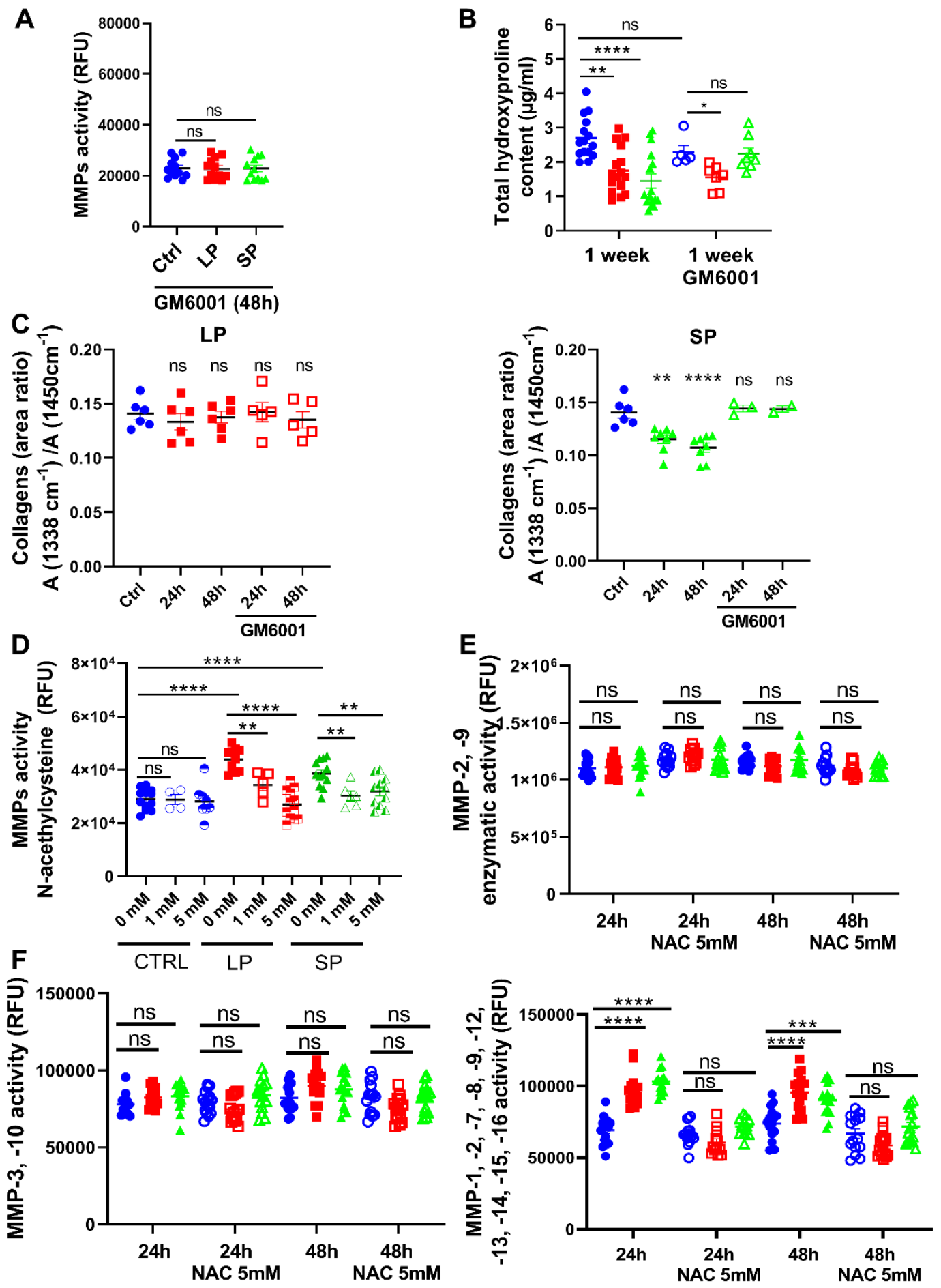

Figure 5. Pharmacological MMPs inhibitor GM6001 partly restores dermal substitute collagens content altered by ROS-dependent MMPs over-activation. A. Quantification by fluorimetry of endogenously active MMPs in supernatant $48 \mathrm{~h}$ after electrostimulation in the presence of GM6001. B. Hydroxyproline content in the whole dermal substitute 1 week after electrostimulation, cultured in the presence (blank symbols) or absence of GM6001 (full symbols). Statistical analysis between the two controls was analyzed with Unpaired t-test. $\mathbf{C}$. Collagen indicator in the bottom side (enriched in ECM) of dermal substitutes measured by FTIR-ATR 24h and 48h after LP and SP electrostimulation in the presence (blank symbols) or absence of GM6001 (full symbols). D. Quantification by fluorimetry of endogenously active 
MMPs in supernatant $24 \mathrm{~h}$ after electrostimulation and culture in the presence of $1 \mathrm{mM}$ and $5 \mathrm{mM}$ ROS inhibitor $N$-acetyl-L-cysteine (NAC). E. MMP-2 and -9 gelatinase activity was quantified by fluorimetry in presence or absence of 5mM NAC. F. MMPs activity against specific substrates was quantified by fluorimetry in presence or absence of $5 \mathrm{mM}$ NAC. Control condition ( $\mathrm{Ctrl} \bullet$ ), long pulses ( $\mathrm{LP} \square)$, and short pulses (SP $\Delta$ ) protocols.

Inactive zymogen pro-MMPs are known to be proteolytically activated in the extracellular space by endogenous proteases and other active MMPs or to be activated in response to exogenous signals such as low pH, heat, reactive oxygen species (ROS) (Amălinei et al. 2007; Kähäri and Saarialho-Kere 1997). Low pH can reasonably be ruled out because of the buffering of both pulsing and cell culture medium. Heat is a parameter that can also be excluded as the pulsing buffer and electric parameters are designed to remain in athermal conditions (Kotnik et al. 2019). In contrast, lipids peroxidation and ROS production have been shown to occur with PEFs (Kotnik et al. 2019). Increasing concentrations (1mM and $5 \mathrm{mM}$ ) of $N$-acetyl-L-cysteine (NAC), a potent ROS inhibitor that increases cellular pools of free radical scavengers (Zhitkovich 2019), were added to both pulsing buffer (during the application of PEFs) and in cell culture medium (Fig5D). Increasing concentration of the ROS scavenger led to a statistical decrease of MMPs over-activation. This observed dose-response clearly establishes the link between the over-activation of MMPs and the presence of ROS in the environment. At this stage of the investigations, no clear response can be provided concerning the origin and maintenance of these ROS. Given electrostimulation is a brief event (less than 12 seconds), abolished upon transfer of the dermal substitutes from the pulsation buffer to the fresh culture medium a few seconds after electrostimulation, and that ROS halflife is very short due to their inherent instability and high reactivity (Dickinson and Chang 2011), the cellular origin of these ROS is more likely to explain the sustained ROS-dependent over-activation of MMPs observed for at least $48 \mathrm{~h}$. In order to better discriminate the role of specific MMPs in ROS-dependant over-activation, we performed experiments with MMP- 
specific substrates (Fig5E, F). We demonstrated that gelatinase MMP-2 and -9 as well as stromelysin MMP-3 and -10 were not activated by electrostimulation, even if MMP-3 was undoubtedly the most abundant MMP at protein level ( $\mu$ g range compared to ng for MMP-1 and -9 and pg for MMP-2) (Fig 4A). It thus appears that the observed over-activation of ROSdependent MMPs was due to the activity of one or more of the following MMPs, namely MMP-1, $-7,-8,-12,-13,-14,-15,-16$, without being able to experimentally identify more precisely the responsible ones. Interestingly, the over-activity of the collagenases MMP-1, -8 and -13 can be linked with the observed decrease in tissue collagen's content (Fig 3A, B).

Pulsed electric fields down-regulated pro-fibrosis inducer TGF- $\beta 1$. Fibrosis results from changes in collagen expression, biosynthesis, enzymatic cross-linking, and degradation by MMPs (Ricard-Blum et al. 2018). These molecular modifications leading to a fibrotic signature are primarily regulated by TGF- $\beta 1$, considered the major pro-fibrogenic inducer (Meng et al. 2016). Interestingly, our experiments show that PEFs significantly downregulated TGF- $\beta 1$ both at mRNA and protein levels (Fig6A, B). To go further, we analyzed other factors known to be pro-fibrogenic and associated with fibrotic diseases, namely interleukin IL-4 and IL-13 (Wynn 2004), but no change was observed at protein levels (Fig6C, D). To enrich the discussion on the therapeutic potential of PEFs in the context of fibrosis, it is essential to emphasize that they induced a drastic decrease in the gene expression of LOXL4 and transglutaminase TG2 (Fig 3D, E), which are known to play an important role in the fibrotic process when overexpressed (Grenard et al. 2001; Benn et al. 2019; Chen et al. 2020). 

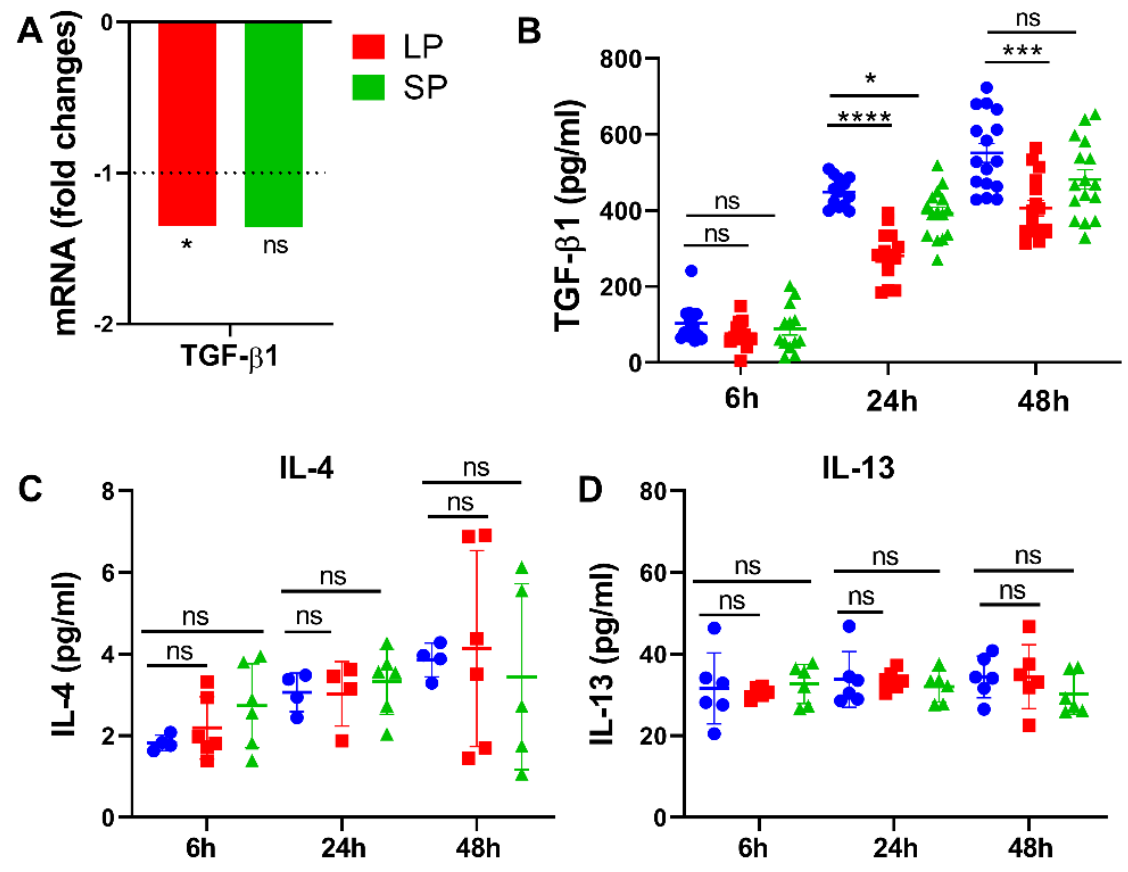

Figure 6. Pulsed electric fields down-regulate pro-fibrosis inducer TGF- $\beta 1$. A. Modulation of TGF- $\beta 1$ mRNA 4 h after electrostimulation. E. TGF- $\beta 1$ expression quantified in the supernatant by ELISA. C. IL-4 expression quantified in the supernatant by ELISA. D. IL-13 expression quantified in the supernatant by ELISA. Control condition (Ctrl •), long pulses (LP $\square$ ), and short pulses (SP $\Delta$ ) protocols.

CONCLUSION. Our results indicate that PEFs are prompt to favor collagens remodeling through both a transient decrease in its production and an increase in its degradation through MMPs sustained activation depending on ROS. The determination of the origin of these ROS is beyond the scope of this work but would clearly open an outlook for further studies. Furthermore, our experimental data prove the ability of the pulsed electric field to downregulate at both mRNA and protein level the TGF- $\beta$, the master regulator of fibrosis, together with a drastic decrease in the gene expression of major enzymes involved in ECM crosslinking (LOXs and transglutaminases). Taken together, these results open up realistic and relevant prospects for PEF technology, without any drug, in the context of fibrosis treatment. All these findings can be excitingly correlated with observations realized by clinicians using short pulse (SP) protocol to deliver anti-tumor drugs, whom commonly observed aesthetic and 
functional healing of sites treated with electrochemotherapy (Glass et al. 1997; Marty et al. 2006; Kis et al. 2012), and by patients themselves, who underlined an improvement in wound healing, and aesthetic impairment (Campana et al. 2009). To conclude, PEFs application to locally and transiently remodel the extracellular matrix present a high and easy translational potential. Indeed, these types of electrical parameters are nowadays used in clinics as an anticancer treatment, meaning that validated apparatus (pulsed electric field generator, electrodes, dosimetry...) are available and clinicians are used to, and well-trained to apply this kind of protocol.

\section{MATERIAL \& METHODS}

Human primary cell culture. Primary human dermal fibroblasts were isolated from 4-years old foreskin biopsy commercially available (Icelltis, France) (Gibot et al. 2010). (Gibot et al. 2010). Ethical approval has been obtained by the supplier from the French Ministry of Higher Education, Research and Innovation (\#AC-2019-3444) and written, informed consents from the guardians of the children were obtained. Cells were grown in DMEM GlutaMAX (Gibco \#10569010) supplemented with 10\% of heat-inactivated fetal calf serum (Gibco \#10270106), $100 \mathrm{U} / \mathrm{ml}$ penicillin, and $100 \mu \mathrm{g} / \mathrm{ml}$ streptomycin (Gibco \#15140122), at $37^{\circ} \mathrm{C}$ in a humidified atmosphere at $5 \% \mathrm{CO}_{2}$. Cells were regularly tested negative for mycoplasma (MycoAlert detection kit, Lonza \#LT07-318).

Reconstruction of human 3D dermal substitutes. Human dermal tissues were generated by tissue-engineering as previously described (Gibot et al. 2017). 30,000 cells/ $\mathrm{cm}^{2}$ primary human dermal fibroblasts were seeded in 24-well plates containing anchoring paper (Whatman \#1004150). Cells were cultivated for 4 weeks in medium supplemented with $50 \mu \mathrm{g} / \mathrm{ml}$ ascorbic acid (Sigma \#A4034, Merck KGaA, Darmstadt, Germany). 


\section{Pulsed electric field application to dermal substitutes to induce reversible}

electroporation. Two stainless steel, flat, parallel electrodes $(0.8 \mathrm{~cm}$ between electrodes, $1 \mathrm{~cm}$ long) (Megastil, Ljubljana, Slovenia) were placed on the top of dermal tissue, covering all the cell area, and immersed in pulsing buffer $\left(10 \mathrm{mM} \mathrm{K}_{2} \mathrm{HPO}_{4} / \mathrm{KH}_{2} \mathrm{PO}_{4}, 1 \mathrm{mM} \mathrm{MgCl}, 250 \mathrm{mM}\right.$ sucrose, pH 7.4 in sterile water) (Madi et al. 2015; Madi et al. 2016) (FigS5A). A Btech electro-cell S20 generator (LeroyBiotech, France) was used to deliver square-wave electric pulses at room temperature. Electric parameters applied were for the long-pulses protocol (LP): 10 pulses of $5 \mathrm{~ms}$ long, $1 \mathrm{~Hz}, 600 \mathrm{~V} / \mathrm{cm}$ and for the short-pulses protocol (SP): 8 pulses of $100 \mu$ s long, $1 \mathrm{~Hz}, 1000 \mathrm{~V} / \mathrm{cm}$ (FigS5B). Millisecond pulses (LP protocols) are classically used to improve nucleic acids delivery thanks to electrophoretic force, while microsecond pulses (SP protocol) are used for small antitumor drugs delivery. These electrical conditions were similar to those applied in clinics for drug delivery (Gehl et al. 2018; Nuccitelli 2019) and well-characterized to induce transient and reversible cell electroporation not inducing cell death. They induced cell permeabilization in the entire depth of the tissue (FigS5C, D) (Madi et al. 2016), while preserving cell viability (FigS5E).

Electron microscopy. For transmission and scanning electron microscopy characterization of 4-weeks old control (non-electrostimulated) tissues, dermal substitutes were fixed in $2 \%$ glutaraldehyde diluted in $0.1 \mathrm{M}$ Sorensen phosphate buffer $(\mathrm{pH} 7.4)$ for $24 \mathrm{~h}$ at $4^{\circ} \mathrm{C}$ and processed as classically described in the literature for tissues. Observations were carried out using Hitachi HT7700 transmission electron microscope and FEG scanning electron microscope FEI Quanta 250.

Second-harmonic generation (SHG). Organized fibrillar collagens bundles were imaged by SHG using a multi-photon microscope LSM 7MP (Carl Zeiss SAS, Jena, Germany). The total thickness of the dermal substitute (approximately $50 \mu \mathrm{m}$ ) was imaged. 


\section{Fourier-Transform Infrared-Attenuated Total Reflectance (FTIR-ATR). FTIR-ATR}

spectra were performed using a Nicolet 5700 (ThermoFisher Scientific, Waltham, MA, USA) equipped with ATR accessory (Smart Orbit with a type IIA diamond crystal, refractive index 2.4) with a $\mathrm{KBr}$ beam splitter and a MCT/B detector. The penetration depth of the evanescent wave into biological tissue was estimated between 0.4 and $3.6 \mu \mathrm{m}$. Hydrated dermal substitutes were laid on the ATR device and dried for 20 min at ambient temperature before spectral acquisition. The top side and the bottom side were successively placed onto the crystal. Spectra were recorded over the region of $4000-450 \mathrm{~cm}^{-1}$ with a spectral resolution of $2 \mathrm{~cm}^{-1}$ and 32 accumulations. A background spectrum was recorded before each experiment and subtracted from the sample spectrum. Data were collected using Omnic 8.0 (ThermoFisher Scientific). Then spectra were baseline corrected, smoothed (11 points Savitzky Golay) and normalized to the amide II $\left(1540-1550 \mathrm{~cm}^{-1}\right)$. The spectra presented per group of samples were calculated by averaging the spectra of all samples within each group. To quantify the different biological components, the areas of the specific absorption bands were computed from the individual spectrum of each sample, and the appropriate ratio of areas was used according to literature data (Staniszewska et al. 2014; Wang et al. 2005).

Transcriptomic analysis of electrostimulated dermal substitutes. RNAs were extracted $4 \mathrm{~h}$ after dermal substitutes electrostimulation using RNeasy Mini kit (Qiagen \#74104). The yield and integrity of the extracted RNAs were confirmed on Bioanalyzer 2100 Expert (Agilent). Differential gene expression was studied by transcriptomic using Clariom S Affymetrix chips on Genome and Transcriptome (GeT) platform of Genotoul (Toulouse, France). Data analysis was performed with TAC software, and expression analysis settings were: Gene-Level Fold Change <-2 or $>2$; Gene-Level FDR <0,05; Anova Method: ebayes.

Quantification of hydroxyproline content. Total hydroxyproline content of whole dermal substitutes was measured using the Hydroxyproline Assay Kit (Sigma \#MAK008). A specific 
set of experiments was led in the presence of $100 \mu \mathrm{M}$ of pan-MMPs pharmacological inhibitor GM6001 (Sigma \#CC1010). GM6001 was added to the culture medium immediately after electric field applications, and renewed at each cell culture medium change.

Quantification of metalloproteinases (MMPs) activity. Quantification of global MMPs activity in the supernatant was carried out using SensoLyte520 Generic MMP Assay Kit (Anaspec \#AS-71158) allowing detecting simultaneously the activity of MMP-1, 2, 3, 7, 8, 9, 12, 13, and 14. Two distinct strategies were led: 1) quantification of the total MMPs activity after chemical activation with 4-aminophenylmercuric acetate (APMA) for $4 \mathrm{~h}$ at $37^{\circ}$ according to manufacturer pieces of advices permits to quantify the total amount of (pro)MMPs in supernatant, and 2) quantification of endogenously active MMPs in the supernatant. A set of experiments was carried out in the presence of $100 \mu \mathrm{M}$ GM6001 in cell culture medium or in the presence of $N$-acetyl-L-cysteine (NAC, Sigma \#A7250) in both pulsing buffer and cell culture medium. Specific MMPs activity was analyzed using commercial substrates according to manufacturer's instructions: MMP-2, -9 (Gelatin Degradation Assay Kit (\#ab234057)), MMP-3, -10 (R\&D systems \#ES002) and other MMPs (R\&D systems \#ES001).

ELISA quantifications. Supernatants were harvested at $6 \mathrm{~h}, 24 \mathrm{~h}, 48 \mathrm{~h}$ after electrostimulation and stocked at $-80{ }^{\circ} \mathrm{C}$ to be used within a month. Following ELISA kits were used strictly according to manufacturer's protocols: Pro-Collagen I alpha 1 DuoSet ELISA kit (R\&D systems, \#DY008), TGF- $\beta 1$ DuoSet ELISA kit (R\&D systems, \#DY007), TIMP-3 (Elabscience, \#E-EL-H1454), MMP-1 (ELISA Genie, \#HUFI00205), MMP-2 (ELISA Genie, \#HUFI00017), MMP-3 (ELISA Genie, \# HUFI00208), MMP-9 (ELISA Genie, \# HUFI00211), IL-4 and IL-13 (V-PLEX Proinflammatory Panel 1 Human Kit, MSD, \# K15049D). 
Statistical analyses. Data analysis was performed using GraphPad Prism 8 Software (La Jolla, CA, USA), and independent biological replicates were plotted and expressed as mean \pm SEM (standard error to the mean). Data have been statistically analyzed using one-way ANOVA followed by Dunnett's post-test to compare every condition (LP, SP) to the control one $(0 \mathrm{~V} / \mathrm{cm})$. Statistics are expressed relative to the control condition $(0 \mathrm{~V} / \mathrm{cm})$. ns: nonsignificant, $* \mathrm{p}<0.05, * * \mathrm{p}<0.01, * * * \mathrm{p}<0.001$ and $* * * * \mathrm{p}<0.0001$

DATA AVAILABILITY. The transcriptomic data discussed in this publication have been deposited in NCBI's Gene Expression Omnibus (Edgar et al. 2002) and are accessible through $\begin{array}{llll}\text { GEO Series } & \text { accession } & \text { number } & \text { GSE180644 }\end{array}$ (https://www.ncbi.nlm.nih.gov/geo/query/acc.cgi?acc=GSE180644).

ORCID Gouarderes S (0000-0001-9080-7876); Doumard L (0000-0001-9407-7989); Dandurand J (0000-0001-7287-2973); Vicendo P (0000-0001-5874-1547); Golberg A (00000001-8782-8879); Samouillan V (0000-0003-0571-3985); Gibot L (0000-0001-7255-4123)

CONFLICT OF INTEREST. The authors state no conflict of interest.

ACKNOWLEDGEMENTS. This research was funded by the French Agence Nationale de la recherche (ANR-17-CE19-0013-01) and performed in the scope of HAPPYBIO GDR. Multiplex ELISAs were read with the technological support of Genoskin company (Toulouse). We want to acknowledge the GeT Genotoul technological platform that realized the transcriptomic analyses, especially Nathalie Marsaud for her help in optimizing nucleic 
acids extraction from the substitutes, and Dr Elisabeth Bellard for her valuable help for the SHG imaging on TRI-Genotoul platform. We would like to warmly thanks Jean-Michel Martin (ICT) and Loïck Royant (Leroy Biotech) for data extractions from the electropulsator, and Dr Mingotaud for her helpful scientific discussions. Lab2screen is acknowledged for English proofreading and editing.

AUTHOR'S CONTRIBUTIONS STATEMENT. Investigation: SG, CO, LD, JD, IF; Formal Analysis: SG, CO, VS; Visualization: SG, CO, LG; Validation: SG; Writing original draft: SG, CO, AG, VS, LG; Writing - review and editing: SG, AG, VS, LG; Conceptualization: PV, AG, VS, LG; Methodology: LG; Funding acquisition: LG; Supervision: LG.

\section{REFERENCES}

Amălinei C, Căruntu I-D, Bălan RA. Biology of metalloproteinases. Rom J Morphol Embryol. 2007;48(4):323-34

Athanasiou KA, Eswaramoorthy R, Hadidi P, Hu JC. Self-organization and the self-assembling process in tissue engineering. Annu. Rev. Biomed. Eng. 2013;15:115-36

Benn MC, Weber W, Klotzsch E, Vogel V, Pot SA. Tissue transglutaminase in fibrosis - more than an extracellular matrix cross-linker. Curr. Opin. Biomed. Eng. 2019;10:156-64

Campana LG, Mocellin S, Basso M, Puccetti O, De Salvo GL, Chiarion-Sileni V, et al. Bleomycin-Based Electrochemotherapy: Clinical Outcome from a Single Institution's Experience with 52 Patients. Ann. Surg. Oncol. 2009;16(1):191-9

Chen W, Yang A, Jia J, Popov YV, Schuppan D, You H. Lysyl Oxidase (LOX) Family Members: Rationale and Their Potential as Therapeutic Targets for Liver Fibrosis. Hepatology. John Wiley \& Sons, Ltd; 2020;72(2):729-41

Collighan RJ, Griffin M. Transglutaminase 2 cross-linking of matrix proteins: biological significance and medical applications. Amino Acids. Springer; 2009;36(4):659-70

Davalos RV, Mir LM, Rubinsky B. Tissue Ablation with Irreversible Electroporation. Ann. Biomed. Eng. 2005;33(2):223 
Dickinson $\mathrm{BC}$, Chang $\mathrm{CJ}$. Chemistry and biology of reactive oxygen species in signaling or stress responses. Nat. Chem. Biol. 2011;7(8):504-11

Eden E, Navon R, Steinfeld I, Lipson D, Yakhini Z. GOrilla: a tool for discovery and visualization of enriched GO terms in ranked gene lists. BMC Bioinformatics. BioMed Central; 2009;10(1):1-7

Edgar R, Domrachev M, Lash AE. Gene Expression Omnibus: NCBI gene expression and hybridization array data repository. Nucleic Acids Res. 2002;30(1):207-10

Frantz C, Stewart KM, Weaver VM. The extracellular matrix at a glance. J. Cell Sci. The Company of Biologists Ltd; 2010;123(24):4195-200

Garner AL, Torres AS, Klopman S, Neculaes B. Electrical stimulation of whole blood for growth factor release and potential clinical implications. Med. Hypotheses. 2020;143:110105

Geboers B, Scheffer HJ, Graybill PM, Ruarus AH, Nieuwenhuizen S, Puijk RS, et al. High-Voltage Electrical Pulses in Oncology: Irreversible Electroporation, Electrochemotherapy, Gene Electrotransfer, Electrofusion, and Electroimmunotherapy. Radiology. Radiological Society of North America; 2020;295(2):254-72

Gehl J, Sersa G, Matthiessen LW, Muir T, Soden D, Occhini A, et al. Updated standard operating procedures for electrochemotherapy of cutaneous tumours and skin metastases. Acta Oncol. 2018;57(7):874-82

Gelse K. Collagens-structure, function, and biosynthesis. Adv. Drug Deliv. Rev. 2003;55(12):1531-46

Gibot L, Galbraith T, Bourland J, Rogic A, Skobe M, Auger FA. Tissue-engineered 3D human lymphatic microvascular network for in vitro studies of lymphangiogenesis. Nat. Protoc. 2017;12:1077

Gibot L, Galbraith T, Huot J, Auger FA. A Preexisting Microvascular Network Benefits In Vivo Revascularization of a Microvascularized Tissue-Engineered Skin Substitute. Tissue Eng. Part A. 2010;16(10):3199-206

Glass LF, Jaroszeski M, Gilbert R, Reintgen DS, Heller R. Intralesional bleomycin-mediated electrochemotherapy in 20 patients with basal cell carcinoma. J. Am. Acad. Dermatol. 1997;37(4):596-9

Golberg A, Villiger M, Broelsch GF, Quinn KP, Albadawi H, Khan S, et al. Skin regeneration with all accessory organs following ablation with irreversible electroporation. J. Tissue Eng. Regen. Med. 2018;12(1):98-113

Golberg A, Villiger M, Khan S, Quinn KP, Lo WCY, Bouma BE, et al. Preventing Scars after Injury with Partial Irreversible Electroporation. J. Invest. Dermatol. 2016;136(11):2297-304

Gouarderes S, Doumard L, Vicendo P, Mingotaud A-F, Rols M-P, Gibot L. Electroporation does not affect human dermal fibroblast proliferation and migration properties directly but indirectly via the secretome. Bioelectrochemistry. 2020a;134:107531

Gouarderes S, Mingotaud A-F, Vicendo P, Gibot L. Vascular and extracellular matrix remodeling by physical approaches to improve drug delivery at the tumor site. Expert Opin. Drug Deliv. Taylor \& Francis; 2020b;0(0):1-24 
Grenard P, Bresson-Hadni S, El Alaoui S, Chevallier M, Vuitton DA, Ricard-Blum S. Transglutaminasemediated cross-linking is involved in the stabilization of extracellular matrix in human liver fibrosis. J. Hepatol. 2001;35(3):367-75

Griffin M, Casadio R, Bergamini CM. Transglutaminases: Nature's biological glues. Biochem. J. 2002;368(2):377-96

Hynes RO, Naba A. Overview of the Matrisome-An Inventory of Extracellular Matrix Constituents and Functions. Cold Spring Harb. Perspect. Biol. 2012;4(1):a004903

Ivey JW, Bonakdar M, Kanitkar A, Davalos RV, Verbridge SS. Improving cancer therapies by targeting the physical and chemical hallmarks of the tumor microenvironment. Cancer Lett. 2015/12/24 ed. 2016;380(1):330-9

Kähäri V-M, Saarialho-Kere U. Matrix metalloproteinases in skin. Exp. Dermatol. 1997;6(5):199-213

Kis E, Baltás E, Kinyó Á, Varga E, Nagy N, Gyulai R, et al. Successful Treatment of Multiple Basaliomas with Bleomycin-based Electrochemotherapy: A Case Series of Three Patients with Gorlin-Goltz Syndrome. Acta Derm Venereol. 2012;92(6):648-51

Kotnik T, Rems L, Tarek M, Miklavčič D. Membrane Electroporation and Electropermeabilization: Mechanisms and Models. Annu. Rev. Biophys. 2019;48(1):63-91

Madi M, Rols M-P, Gibot L. Efficient In Vitro Electropermeabilization of Reconstructed Human Dermal Tissue. J. Membr. Biol. 2015;248(5):903-8

Madi M, Rols M-P, Gibot L. Gene Electrotransfer in 3D Reconstructed Human Dermal Tissue. Curr Gene Ther. 2016;16(2):75-82

Magnan L, Labrunie G, Marais S, Rey S, Dusserre N, Bonneu M, et al. Characterization of a CellAssembled extracellular Matrix and the effect of the devitalization process. Acta Biomater.

2018;82:56-67

Marty M, Sersa G, Garbay JR, Gehl J, Collins CG, Snoj M, et al. Electrochemotherapy - An easy, highly effective and safe treatment of cutaneous and subcutaneous metastases: Results of ESOPE (European Standard Operating Procedures of Electrochemotherapy) study. Eur. J. Cancer Suppl. 2006;4(11):3-13

Meng X, Nikolic-Paterson DJ, Lan HY. TGF- $\beta$ : the master regulator of fibrosis. Nat. Rev. Nephrol. Nature Publishing Group; 2016;12(6):325

Naba A, Clauser KR, Ding H, Whittaker CA, Carr SA, Hynes RO. The extracellular matrix: Tools and insights for the "omics" era. Matrix Biol. 2016;49:10-24

Nuccitelli R. Application of pulsed electric fields to cancer therapy. Bioelectricity. Mary Ann Liebert, Inc., publishers 140 Huguenot Street, 3rd Floor New ...; 2019;1(1):30-4

Ricard-Blum S. The Collagen Family. Cold Spring Harb. Perspect. Biol. 2011;3(1):a004978

Ricard-Blum S, Baffet G, Théret N. Molecular and tissue alterations of collagens in fibrosis. Matrix Biol. 2018;68-69:122-49 
Sanden KW, Kohler A, Afseth NK, Böcker U, Rønning SB, Liland KH, et al. The use of Fourier-transform infrared spectroscopy to characterize connective tissue components in skeletal muscle of Atlantic cod (Gadus morhua L.). J. Biophotonics. Wiley Online Library; 2019;12(9):e201800436

Scott I, Yamauchi M, Sricholpech M. Lysine post-translational modifications of collagen. Essays Biochem. Portland press; 2012;52:113-33

Staniszewska E, Malek K, Baranska M. Rapid approach to analyze biochemical variation in rat organs by ATR FTIR spectroscopy. Spectrochim. Acta - Part Mol. Biomol. Spectrosc. Elsevier B.V.; 2014;118:981-6

Szondy Z, Korponay-Szabó I, Király R, Sarang Z, Tsay GJ. Transglutaminase 2 in human diseases. BioMedicine. 2017/08/25 ed. EDP Sciences; 2017;7(3):15-15

Trackman PC. Lysyl oxidase isoforms and potential therapeutic opportunities for fibrosis and cancer. Expert Opin. Ther. Targets. Taylor \& Francis; 2016;20(8):935-45

Wang $Q$, Sanad W, Miller LM, Voigt A, Klingel K, Kandolf R, et al. Infrared imaging of compositional changes in inflammatory cardiomyopathy. Vib. Spectrosc. 2005;38(1-2):217-22

Winkler J, Abisoye-Ogunniyan A, Metcalf KJ, Werb Z. Concepts of extracellular matrix remodelling in tumour progression and metastasis. Nat. Commun. Nature Publishing Group; 2020;11(1):1-19

Wynn TA. Fibrotic disease and the TH 1/TH 2 paradigm. Nat. Rev. Immunol. Nature Publishing Group; 2004;4(8):583-94

Yarmush ML, Golberg A, Serša G, Kotnik T, Miklavčič D. Electroporation-Based Technologies for Medicine: Principles, Applications, and Challenges. Annu. Rev. Biomed. Eng. 2014;16(1):295-320

Zhitkovich A. N-Acetylcysteine: Antioxidant, Aldehyde Scavenger, and More. Chem. Res. Toxicol. American Chemical Society; 2019;32(7):1318-9 


\section{Supplementary text S1: Vibrational signature of human dermal substitutes}

The FTIR-ATR spectra of the top and bottom sides of dermal substitute in control condition, in the [3800-1300 $\left.\mathrm{cm}^{-1}\right]$ range is shown in Fig S1a. Main absorption bands detected from the spectrum of both the bottom and/or top sides, and their respective assignment are summarised in Table S1. Those were interpreted according to values reported in literature.
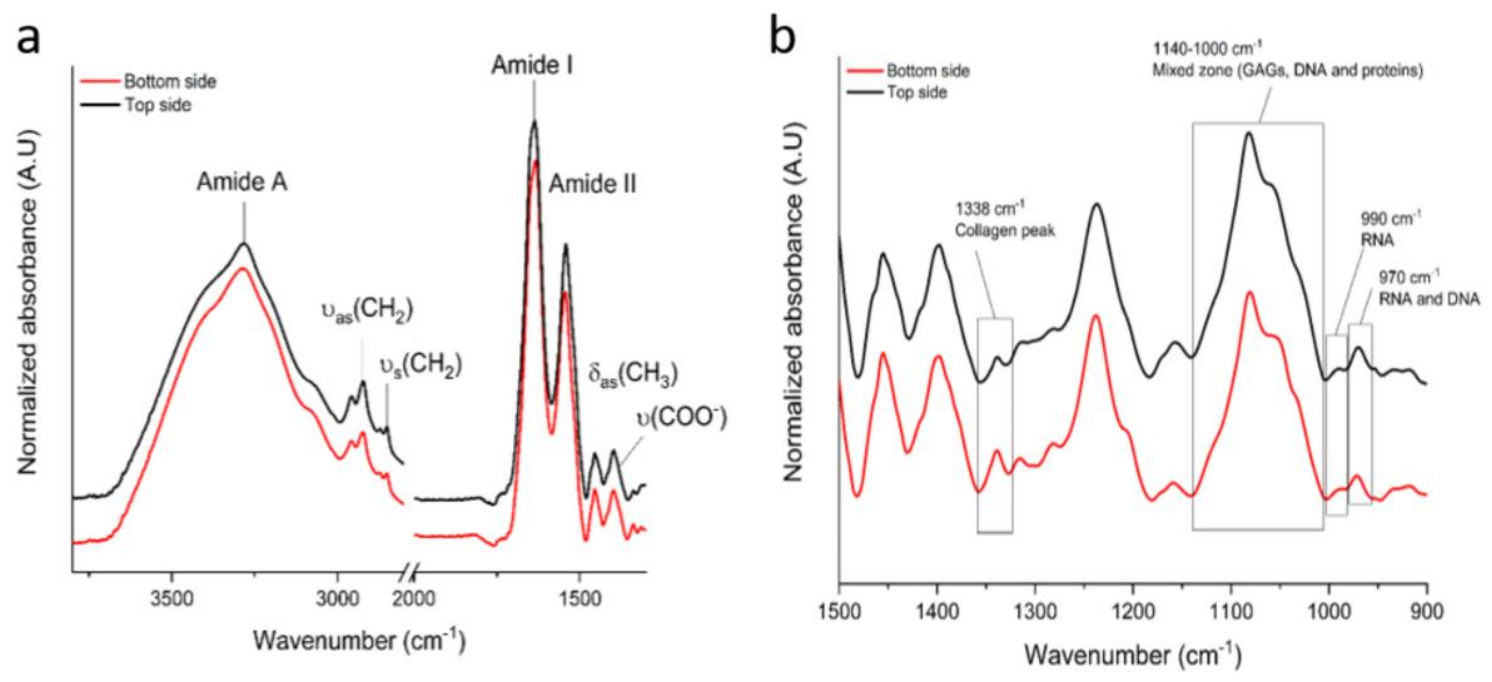

Figure S1. Mean FTIR-ATR spectra of dermal substitute in control condition in the $\left[3800-1300 \mathrm{~cm}^{-1}\right]$ range $(a)$ and in the $\left[1500-900 \mathrm{~cm}^{-1}\right]$ range $(b)$.

In the [3000-2800 $\mathrm{cm}^{-1}$ ] range, asymmetric and symmetric stretching absorption modes of methylene group $v_{\text {as }}\left(\mathrm{CH}_{2}\right)$ and $v_{\mathrm{s}}\left(\mathrm{CH}_{2}\right)$ located at $2927 \mathrm{~cm}^{-1}$ and $2850 \mathrm{~cm}^{-1}$ respectively, are mainly associated with lipids and widely used to quantify them. In the [1800-1500 $\mathrm{cm}^{-1}$ spectral region, protein absorption is represented by Amide I and Amide II bands. The amide I band, mainly arising from $\mathrm{C}=\mathrm{O}$ stretching, is very sensitive to secondary structures in proteins. It must be underlined that $\mathrm{O}-\mathrm{H}$ bending vibration of water is superimposed to the Amide I vibration in hydrated samples. In contrast with Amide I, Amide II, that mostly combines N-H bending coupled to C-N stretching, is not sensitive to water and largely used as a normalisation peak to compare whole spectra. Another absorption mainly attributed to proteins is the methyl bending $\delta_{\text {as }}\left(\mathrm{CH}_{3}\right)$ visible at $1452 \mathrm{~cm}^{-1}$, whose area is used in further ratio indicators. The enlargement of the $\left[1500-900 \mathrm{~cm}^{-1}\right]$ range (Fig S1b), generally known as the fingerprint region, can reveal subtler molecular differences in biological tissues.

The $1338 \mathrm{~cm}^{-1}$ band (wagging of proline side chain) is thus referenced in literature as a specific absorption of collagen and can be used to quantify this major ECM protein (Tang et al, 2017; Belbachir et al, 2009). The area ratio $\mathrm{A}\left(1338 \mathrm{~cm}^{-1}\right) / \mathrm{A}\left(1452 \mathrm{~cm}^{-1}\right)$ is thus computed to determine collagen content from tissue side.

As referenced in Table $\mathrm{S} 1$, the $1082 \mathrm{~cm}^{-1}$ band absorption is mainly assigned to the $v_{\mathrm{s}}\left(\mathrm{PO}_{2}^{-}\right)$of DNA and phospholipids of cell membranes (Wood et al, 2016), with the contribution of the $\mathrm{C}-\mathrm{O}$ of collagen and glycosaminoglycans. In addition, the 1060 and $1032 \mathrm{~cm}^{-1}$ are mainly assigned to the $\mathrm{C}-\mathrm{O}$ stretching vibration of ribose and other carbohydrates residues (Sanden et al, 2019). This area ratio $\mathrm{A}\left(1140-1000 \mathrm{~cm}^{-1}\right) / \mathrm{A}\left(1452 \mathrm{~cm}^{-1}\right)$ zone is thus assigned to a "mixed" zone, peculiar sensitive to cellular material and GAGs.

Finally, the 990 band is specifically assigned to uracil ring motions of RNA while the $970 \mathrm{~cm}^{-}$ ${ }^{1}$ is assigned to DNA (mainly) and RNA ribose-phosphate skeletal motions (Wood et al, 
2016). The area ratio $\mathrm{A}\left(970 \mathrm{~cm}^{-1}\right) / \mathrm{A}\left(1452 \mathrm{~cm}^{-1}\right)$ is used to determine the presence of cellular materiel in each side.

Table S1: FTIR assignment of bottom and/or top side control condition dermal substitute

\begin{tabular}{|c|c|}
\hline $\begin{array}{l}\text { Band position } \\
\qquad / \mathrm{cm}^{-1}\end{array}$ & Assignment \\
\hline $3600-3000$ & $\begin{array}{l}\text { Amide } A \text { : Mainly } v(\mathrm{~N}-\mathrm{H}) \text { of protein }+v(\mathrm{O}-\mathrm{H}) \text { of water (largely dependent } \\
\text { on hydration) }\end{array}$ \\
\hline $\begin{array}{l}2958,2925,287 \\
0,2850\end{array}$ & $v_{\text {as }}\left(\mathrm{CH}_{3}\right), v_{\mathrm{s}}\left(\mathrm{CH}_{3}\right)$ of proteins, $v_{\text {as }}\left(\mathrm{CH}_{2}\right), v_{\mathrm{s}}\left(\mathrm{CH}_{2}\right)$ of lipids \\
\hline $1744-1735$ & $v(C=O)$ of triglycerides, cholesterol esters, phospholipids \\
\hline $1694-1630$ & Amide $\mathrm{I}: v(\mathrm{C}=\mathrm{O})$ of proteins and $\delta(\mathrm{O}-\mathrm{H})$ of water \\
\hline $1558-1542$ & Amide II $: v(\mathrm{C}-\mathrm{N}), \delta(\mathrm{N}-\mathrm{H})$ of proteins \\
\hline 1452 & $\delta_{\text {as }}\left(\mathrm{CH}_{3}\right)$ of proteins \\
\hline $1401-1393$ & $v_{s}\left(\mathrm{COO}^{-}\right)$of proteins and lipids \\
\hline 1338 & $\delta\left(\mathrm{CH}_{2}\right)$ wagging of proline chains (specific collagen band) \\
\hline $1320-1200$ & $\begin{array}{l}\text { Amide III : several modes of vibration of proteins including } v(\mathrm{C}-\mathrm{N}), \delta(\mathrm{N}- \\
\mathrm{H}), \delta(\mathrm{N}-\mathrm{H}), v(\mathrm{C}-\mathrm{C}) \text { and } \delta(\mathrm{C}-\mathrm{H})\end{array}$ \\
\hline $1246-1200$ & $\begin{array}{l}1238 \mathrm{~cm}^{-1}: \delta\left(\mathrm{CH}_{3}\right) \text { specific of ECM (mainly collagen) } \\
1205 \mathrm{~cm}^{-1}: \delta(\mathrm{C}-\mathrm{OH}) \text { specific of ECM (mainly collagen) }\end{array}$ \\
\hline $1200-1180$ & $v(\mathrm{C}-\mathrm{O})$ of proteins and $v(\mathrm{C}-\mathrm{OH})$ of nucleic acids \\
\hline \multirow[t]{5}{*}{$1180-1000$} & $1171 \mathrm{~cm}^{-1}: v_{\text {as }}(\mathrm{CO}-\mathrm{O}-\mathrm{C})$ of cholesterol esters, phospholipids \\
\hline & $1115 \mathrm{~cm}^{-1}: v_{\text {as }}(\mathrm{C}-\mathrm{O})$ of carbohydrates \\
\hline & $\begin{array}{l}1081 \mathrm{~cm}^{-1}: v(\mathrm{C}-\mathrm{O}-\mathrm{C}) \text { of collagen, glycolipids, proteoglycans and } \mathrm{v}_{\mathrm{s}}\left(\mathrm{PO}_{2}^{-}\right) \\
\text {of phospholipids and nucleic acids (DNA) }\end{array}$ \\
\hline & $1061 \mathrm{~cm}^{-1}: v_{\text {as }}(\mathrm{C}-\mathrm{O})$ of carbohydrates \\
\hline & $1032 \mathrm{~cm}^{-1}: v_{\mathrm{s}}(\mathrm{CO}-\mathrm{O}-\mathrm{C})$ of carbohydrates residues in collagen and (GAG)s \\
\hline 990 & RNA uracile ring motions \\
\hline 970 & DNA/ RNA ribose-phosphate skeletal motions \\
\hline
\end{tabular}


Table S2: Visualization of GO (gene ontology) terms by processes in the target gene list using Gorilla tool. We performed enrichment analysis using the GOrilla platform in the transcriptomic dataset (Eden et al, 2009). This analysis allowed to identify GO terms that are significantly overrepresented in the list of differentially expressed genes (the target set) compared to the totality of genes contained on the Affymetrix chip (background set) using the standard Hyper Geometric statistics. Analysis of gene ontology terms by processes show biological processes that were mainly affected by electrostimulation. The 10 most affected processes are presented, ranked by statistical significance.

\begin{tabular}{|c|c|c|c|c|}
\hline GO Term & Description & P-value & FDR q-value & Enrichment \\
\hline \multicolumn{5}{|c|}{ LP protocol } \\
\hline GO:0031323 & regulation of cellular metabolic process & $6.67 \mathrm{E}-29$ & $1.02 \mathrm{E}-24$ & 1.68 \\
\hline GO:0019222 & regulation of metabolic process & $3.16 \mathrm{E}-28$ & $2.42 \mathrm{E}-24$ & 1.63 \\
\hline GO:0080090 & regulation of primary metabolic process & $1.97 \mathrm{E}-25$ & $1.01 \mathrm{E}-21$ & 1.65 \\
\hline GO:0051171 & regulation of nitrogen compound metabolic process & $3.81 \mathrm{E}-25$ & $1.46 \mathrm{E}-21$ & 1.66 \\
\hline GO:0060255 & regulation of macromolecule metabolic process & $2.71 \mathrm{E}-24$ & 8.31E-21 & 1.63 \\
\hline GO:0048523 & negative regulation of cellular process & $2.14 \mathrm{E}-22$ & $5.47 \mathrm{E}-19$ & 1.74 \\
\hline GO:0048519 & negative regulation of biological process & $2.55 \mathrm{E}-21$ & $5.58 \mathrm{E}-18$ & 1.66 \\
\hline GO:0009889 & regulation of biosynthetic process & $3.99 \mathrm{E}-21$ & 7.63E-18 & 1.78 \\
\hline GO:0031326 & regulation of cellular biosynthetic process & $6.39 \mathrm{E}-20$ & $1.09 \mathrm{E}-16$ & 1.76 \\
\hline GO:0031324 & negative regulation of cellular metabolic process & $1.36 \mathrm{E}-19$ & $2.09 \mathrm{E}-16$ & 2.05 \\
\hline \multicolumn{5}{|c|}{ SP protocol } \\
\hline GO:0019222 & regulation of metabolic process & $6.36 \mathrm{E}-14$ & $9.74 \mathrm{E}-10$ & 1.56 \\
\hline GO:0065009 & regulation of molecular function & $1.18 \mathrm{E}-12$ & $9,00 \mathrm{E}-09$ & 1.95 \\
\hline GO:0031323 & regulation of cellular metabolic process & $1.94 \mathrm{E}-12$ & 9.89E-9 & 1.56 \\
\hline GO:0010033 & response to organic substance & $2.33 \mathrm{E}-12$ & 8.92E-9 & 2.21 \\
\hline GO:0048522 & positive regulation of cellular process & 4.38E-12 & $1.34 \mathrm{E}-8$ & 1.62 \\
\hline GO:0048523 & negative regulation of cellular process & $5.41 \mathrm{E}-12$ & $1.38 \mathrm{E}-8$ & 1.68 \\
\hline GO:0048519 & negative regulation of biological process & $1.82 \mathrm{E}-11$ & $3.98 \mathrm{E}-8$ & 1.61 \\
\hline GO:0060255 & regulation of macromolecule metabolic process & $2.07 \mathrm{E}-11$ & $3.96 \mathrm{E}-8$ & 1.54 \\
\hline GO:0048518 & positive regulation of biological process & $2.23 \mathrm{E}-11$ & $3.8 \mathrm{E}-8$ & 1.54 \\
\hline GO:0042221 & response to chemical & $2.36 \mathrm{E}-11$ & $3.61 \mathrm{E}-8$ & 1.99 \\
\hline
\end{tabular}


Table S3. Transcriptomic analyses of differentially expressed genes in "core matrisome" sub-panel. Annotation according to (Naba et al, 2016). The extracellular matrix: Tools and insights for the "omics" era. Matrix Biol. 49, 10-24 (2016)). Genes in bold are modulated after electrostimulation and described in columns "LP" and "SP": fold changes are indicated in brackets after gene symbols, down-regulated genes (green), up-regulated genes (red). Col = Collagens; $\mathrm{PG}=$ Proteoglycans. $\mathrm{p}$-value $<0.05 . \mathrm{n}=4$.

\begin{tabular}{|c|c|c|c|}
\hline & Gene symbol & LP & SP \\
\hline 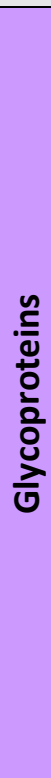 & $\begin{array}{l}\text { ABI3BP; ADIPOQ; "ADIRF-AS1; RP11-96C23.15; MMRN2"; "AEBP1; MIR4649"; AGRN; AMBN; AMELX; } \\
\text { AMELY; BMPER; BSPH1; CDCP2; CILP; CILP2; COCH; COLQ; COMP; CRELD1; CRELD2; CRIM1; CRISPLD1; } \\
\text { CRISPLD2; CTGF; CTHRC1; CYR61; DDX26B; DMBT1; DMP1; DPT; DSPP; ECM1; ECM2; EDIL3; EFEMP1; } \\
\text { EFEMP2; EGFLAM; ELN; ELSPBP1; EMID1; EMILIN1; EMILIN2; EMILIN3; EYS; FBLN1; FBLN2; FBLN5; } \\
\text { FBLN7; FBN1; FBN2; FBN3; "FBN3; mumari"; FGA; FGB; FGG; FGL1; FGL2; FN1; FNDC1; FNDC7; FNDC8; } \\
\text { FRAS1; GAS6; GLDN; HMCN1; HMCN2; IBSP; IGFALS; IGFBP1; IGFBP2; IGFBP3; IGFBP4; IGFBP5; } \\
\text { IGFBP6; IGFBP7; IGFBPL1; IGSF10; KCP; LAMA1; LAMA2; LAMA2; LAMA3; LAMA4; "LAMA5; } \\
\text { MIR4758"; LAMB1; LAMB2; "LAMB3; MIR4260"; LAMB4; LAMC1; LAMC2; LAMC3; LGI1; LGI2; LGI3; } \\
\text { LGI4; "LOC101929319; TNFAIP6"; LRG1; LTBP1; LTBP2; LTBP3; LTBP4; MATN1; MATN2; MATN3; } \\
\text { MATN4; MEPE; MFAP1; MFAP2; MFAP3; MFAP3; MFAP4; MFAP5; MFGE8; MGP; MMRN1; MMRN2; } \\
\text { MXRA5; NDNF; NELL1; NELL2; NID1; NID2; NOV; NPNT; NTN1; NTN3; NTN4; NTN5; NTNG1; NTNG2; } \\
\text { OIT3; OTOG; OTOL1; PAPLN; PCOLCE; PCOLCE2; "PMF1; PMF1-BGLAP; BGLAP"; POMZP3; POSTN; } \\
\text { PXDN; PXDN; PXDNL; RELN; RSPO1; RSPO2; RSPO3; RSPO4; SBSPON; "SLIT1; ARHGAP19 SLIT1"; SLIT2; } \\
\text { SLIT3; SMOC1; SMOC2; SNED1; SNED1; SPARC; SPARCL1; SPON1; SPON2; SPP1; SRPX; SRPX2; SSPO; } \\
\text { SVEP1; TECTA; TECTB; TGFBI; THBS1; THBS2; THBS3; THBS4; THSD4; TINAG; TINAGL1; TNC; TNFAIP6; } \\
\text { TNN; TNR; TNXB; TSKU; TSPEAR; VIT; VTN; VWA1; VWA2; VWA3A; VWA3B; VWA5A; VWA5B1; } \\
\text { VWA5B2; VWA7; VWA9; VWCE; VWDE; VWF; WISP1; WISP2; WISP3; ZP1; ZP2; ZP3; ZP4; ZPLD1; } \\
\text { ZPLD1 }\end{array}$ & $\begin{array}{l}\text { AEBP1; MIR4649 }(-1,76) \\
\text { CRISPLD2 }(-1,69) \text { CTGF } \\
(1,98) \text { DDX26B }(2,75) \\
\text { FNDC1 }(-1,79) \text { IGFBP2 (- } \\
\text { 1,57) IGFBP5 }(-1,54) \\
\text { LAMA3 }(-1,55) \text { LTBP1 } \\
(-1,58) \text { LTBP2 }(-1,88) \\
\text { MFAP1 }(-1,55) \text { MFAP4 (- } \\
2,01) \text { RSPO3 }(1,59) \text { SLIT2 } \\
(1,8) \text { TNC }(-1,51) \text { TNFAIP6 } \\
(3,52)\end{array}$ & $\begin{array}{l}\text { COMP }(-1,76) \text { CRISPLD2 (- } \\
1,71) \text { CTGF }(1,88) \text { EDIL3 (- } \\
\text { 1,72) HMCN1 }(-2,32) \\
\text { IGFBP2 }(-1,6) \text { IGFBP4 (- } \\
\text { 1,52) LAMB1 }(-1,57) \text { LTBP1 } \\
(-2,01) \text { LTBP2 }(-1,74) \\
\text { MFAP4 }(-1,59) \text { NPNT }(-1,5) \\
\text { TNC }(-1,79) \text { TNFAIP6 }(3,33)\end{array}$ \\
\hline 8 & $\begin{array}{l}\text { COL1A1; COL1A2; COL2A1; "COL3A1; MIR3606"; COL4A1; COL4A2; COL4A3; COL4A4; COL4A5; } \\
\text { COL4A6; COL5A1; COL5A2; COL5A3; COL6A1; COL6A2; COL6A2; COL6A2; COL6A3; COL6A5; COL6A6; } \\
\text { "COL7A1; MIR711"; COL8A1; COL8A2; COL9A1; COL9A2; COL9A3; COL10A1; COL11A1; COL11A2; } \\
\text { COL12A1; COL13A1; COL14A1; COL15A1; COL16A1; "COL17A1; MIR936"; COL18A1; COL19A1; } \\
\text { COL20A1; COL21A1; COL22A1; COL23A1; COL24A1; COL25A1; COL26A1; COL27A1; COL28A1; COL4A3 }\end{array}$ & $\begin{array}{l}\text { CoL1A1 }(-1,73) \text { COL5A1 (- } \\
2,19)\end{array}$ & COL5A1 $(-1,59)$ \\
\hline ర్ & $\begin{array}{l}\text { ACAN; ASPN; BCAN; BGN; CHAD; CHADL; DCN; EPYC; ESM1; FMOD; HAPLN1; HAPLN2; HAPLN3; } \\
\text { HAPLN4; HSPG2; IMPG1; IMPG2; KERA; LUM; NCAN; NYX; OGN; OMD; OPTC; PODN; PODN; PODNL1; } \\
\text { PRELP; PRG2; PRG3; PRG4; SPOCK1; SPOCK2; SPOCK3; SRGN; VCAN }\end{array}$ & $\begin{array}{l}\text { BGN }(-1,81) \text { FMOD }(-1,51) \\
\text { PODN }(-1,93) \text { PRELP }(-1,71) \\
\text { SRGN }(1,96)\end{array}$ & $\begin{array}{l}\text { ACAN }(-1,52) \text { BGN }(-2,01) \\
\text { HAPLN3 }(-1,53)\end{array}$ \\
\hline
\end{tabular}


Table S4. Transcriptomic analyses of differentially expressed genes in "matrix-associated proteins" sub-panel. Annotation according to (Naba et al, 2016). Genes in bold are modulated after electrostimulation and described in columns "LP" and "SP": fold changes are indicated in brackets after gene symbols, down-regulated genes (green), up-regulated genes (red). p-value $<0.05$. $n=4$.

\begin{tabular}{|c|c|c|c|}
\hline & Gene symbol & LP & SP \\
\hline 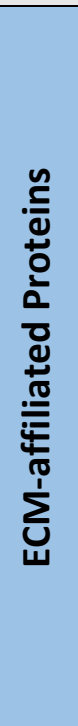 & $\begin{array}{l}\text { ANXA1; ANXA10; ANXA11; ANXA13; ANXA2; ANXA3; ANXA4; ANXA4; ANXA5; ANXA6; ANXA7; ANXA8; } \\
\text { ANXA8; "ANXA8L1; ANXA8"; ANXA9; C1QA; C1QB; C1QC; C1QL1; C1QL2; C1QL3; C1QL4; C1QTNF1; C1QTNF2; } \\
\text { C1QTNF3; C1QTNF4; "C1QTNF5; MFRP"; C1QTNF6; C1QTNF6; C1QTNF7; C1QTNF8; CD209; CLC; CLEC10A; } \\
\text { CLEC11A; CLEC12A; CLEC12B; CLEC14A; CLEC17A; CLEC18A; CLEC18B; CLEC18C; CLEC19A; CLEC1A; CLEC1B; } \\
\text { CLEC2A; CLEC2B; CLEC2D; CLEC2L; CLEC3A; CLEC3B; CLEC4A; CLEC4C; CLEC4D; CLEC4E; CLEC4F; CLEC4G; } \\
\text { CLEC4M; CLEC5A; CLEC6A; CLEC7A; CLEC9A; COLEC10; COLEC11; COLEC12; CSPG4; CSPG5; ELFN1; ELFN2; } \\
\text { ELFN2; EMCN; FCN1; FCN2; FCN3; FREM1; FREM2; FREM3; GPC1; GPC2; GPC3; GPC4; GPC5; GPC6; GPC6; } \\
\text { GREM1; GREM1; GREM1; GREM1; GRIFIN; "HNRNPA1P33; LINC00842; ANXA8L1"; HPX; ITLN1; ITLN2; } \\
\text { LGALS1; LGALS12; LGALS13; LGALS14; LGALS16; LGALS2; LGALS3; LGALS4; "LGALS7; LGALS7B"; LGALS8; } \\
\text { LGALS9; LGALS9B; "LGALS9C; LGALS9B"; LMAN1; LMAN1L; MBL2; MUC1; MUC12; MUC13; MUC15; MUC16; } \\
\text { MUC17; MUC19; MUC2; "MUC20; SDHAP2; MIR570; LINCO0969"; MUC21; MUC22; MUC3A; MUC4; } \\
\text { MUC5AC; MUC5B; MUC6; MUC7; MUCL1; OVGP1; PARM1; PLXDC1; PLXDC2; PLXNA1; PLXNA2; PLXNA3; } \\
\text { PLXNA4; PLXNB1; PLXNB2; PLXNB3; PLXNC1; PLXND1; PROL1; REG1A; REG1B; REG3A; REG3G; REG4; SDC1; } \\
\text { SDC2; SDC3; SDC4; SEMA3A; SEMA3A; SEMA3A; "SEMA3B; MIR6872"; SEMA3C; SEMA3D; SEMA3E; SEMA3F; } \\
\text { SEMA3G; SEMA4A; SEMA4B; SEMA4C; SEMA4D; SEMA4D; SEMA4F; SEMA4G; SEMA5A; SEMA5B; SEMA6A; } \\
\text { SEMA6B; SEMA6C; SEMA6D; SEMA7A; SFTA2; SFTA3; SFTPA1; "SFTPA2; SFTPA1"; SFTPB; SFTPC; SFTPC; } \\
\text { SFTPD; "SPATA13; C1QTNF9 }\end{array}$ & $\begin{array}{l}\text { C1QA }(1,51) \text { CLEC12B } \\
(1,51) \text { CLEC2D }(2,11) \\
\text { CSPG4 } \\
(-1,58) \text { ELFN1 }(-2,54) \\
\text { MUC12 }(1,73) \text { PLXNA1 } \\
(-1,78) \text { PLXNB2 }(-1,5) \\
\text { PLXNC1 }(-1,81) \text { PLXND1 } \\
(-3,12) \text { SDC4 }(1,5) \\
\text { SEMA3A }(1,62) \\
\text { SEMA7A }(-1,71)\end{array}$ & $\begin{array}{l}\text { GPC6 }(-1,58) \text { MUC12 } \\
(1,73) \text { PLXND1 }(-1,97) \\
\text { SDC3 } \\
(-1,58) \text { SDC4 }(1,63) \\
\text { SEMA4G }(1,53)\end{array}$ \\
\hline
\end{tabular}


A2M; A2ML1; ADAM10; ADAM11; ADAM12; ADAM15; ADAM17; ADAM18; ADAM19; ADAM2; ADAM20; ADAM21; ADAM22; ADAM23; ADAM28; ADAM29; ADAM29; ADAM30; ADAM32; ADAM33; ADAM7;

ADAM8; ADAM8; ADAM9; ADAMDEC1; ADAMTS1; ADAMTS10; ADAMTS12; ADAMTS13; ADAMTS13; ADAMTS13; ADAMTS13; ADAMTS13; ADAMTS13; ADAMTS13; ADAMTS13; ADAMTS13; ADAMTS13;

ADAMTS14; ADAMTS15; ADAMTS16; ADAMTS17; ADAMTS17; ADAMTS18; ADAMTS19; ADAMTS2; ADAMTS20; ADAMTS3; ADAMTS4; ADAMTS5; ADAMTS6; ADAMTS7; ADAMTS8; ADAMTS9; ADAMTSL1; ADAMTSL2; ADAMTSL3; ADAMTSL4; ADAMTSL5; AGT; AMBP; ASTL; BMP1; C17orf58; CD109; CELA1; CELA2A; CELA2B; CELA3A; CELA3B; "CEP295NL; TIMP2"; CPAMD8; CPN2; CST1; CST11; CST2; CST3; CST4; CST5; CST6; CST7; CST8; CST9; CST9L; CSTA; CSTB; CSTL1; CTSA; CTSB; CTSB; CTSC; CTSD; CTSE; CTSF; CTSG; CTSH; CTSK; CTSL; CTSO; CTSS; CTSV; CTSW; CTSZ; EGLN1; EGLN2; EGLN3; EGLN3; EGLN3; ELANE; "ENTPD4; LOXL2"; F10; F10; F10; F12; F13A1; F13B; F2; F7; F9; FAM20A; FAM20B; FAM20C; HABP2; HMSD; HPSE; HPSE2; HRG; HTRA1; HTRA3; HTRA3; HTRA4; HYAL1; HYAL2; HYAL3; HYAL4; ITIH1; ITIH2; ITIH3; ITIH4; ITIH5; ITIH6; KAZALD1; KAZALD1; KNG1; KY; LOX; LOXL1; LOXL3; LOXL4; LPA; MASP1; MASP2; MEP1A; MEP1B; MMP1; MMP10; MMP11; MMP12; MMP13; MMP14; MMP15; MMP16; MMP17; MMP19; MMP2; MMP20; MMP21; "MMP23B; MMP23A"; MMP24; MMP25; MMP26; MMP27; MMP28; MMP3; MMP7; MMP8; MMP9; NGLY1; OGFOD1; OGFOD2; P4HA1; P4HA2; P4HA2; P4HA3; P4HTM; PAMR1; PAPPA; PAPPA2; PCSK5; PCSK6; PI3; PLAT; PLAU; PLG; PLOD1; PLOD2; PLOD3; PRSS1; PRSS12; PRSS2; PRSS3; PZP; SERPINA1; SERPINA10; SERPINA11; SERPINA12; SERPINA2; SERPINA3; SERPINA4; SERPINA5; SERPINA6; SERPINA7 SERPINA9; SERPINB1; SERPINB10; SERPINB11; SERPINB12; SERPINB13; SERPINB2; SERPINB3; SERPINB4; SERPINB5; SERPINB6; SERPINB7; SERPINB8; SERPINB9; SERPINC1; SERPIND1; SERPINE1; SERPINE2 SERPINE3; SERPINF1; SERPINF2; SERPING1; SERPINH1; SERPINH1; SERPINI1; SERPINI2; SLPI; SPAM1; ST14; SULF1; SULF2; SULF2; TGM1; TGM2; TGM3; TGM4; TGM4; TGM4; TGM4; TGM4; TGM4; TGM4; TGM5; TGM6; TGM7; TIMP1; TIMP3; TIMP4; TLL1; TLL2; TMPRSS15

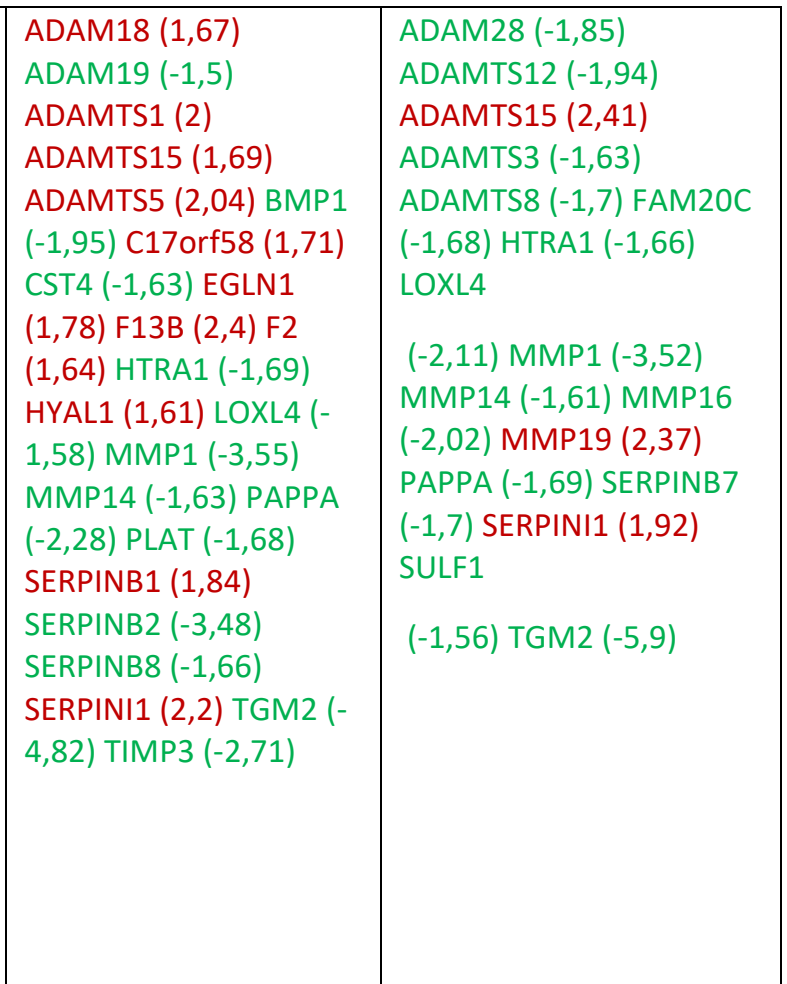




\begin{tabular}{|c|c|c|c|}
\hline 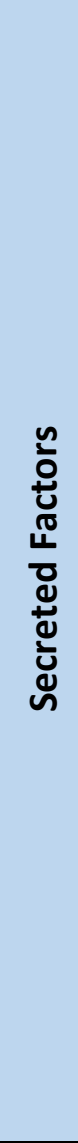 & 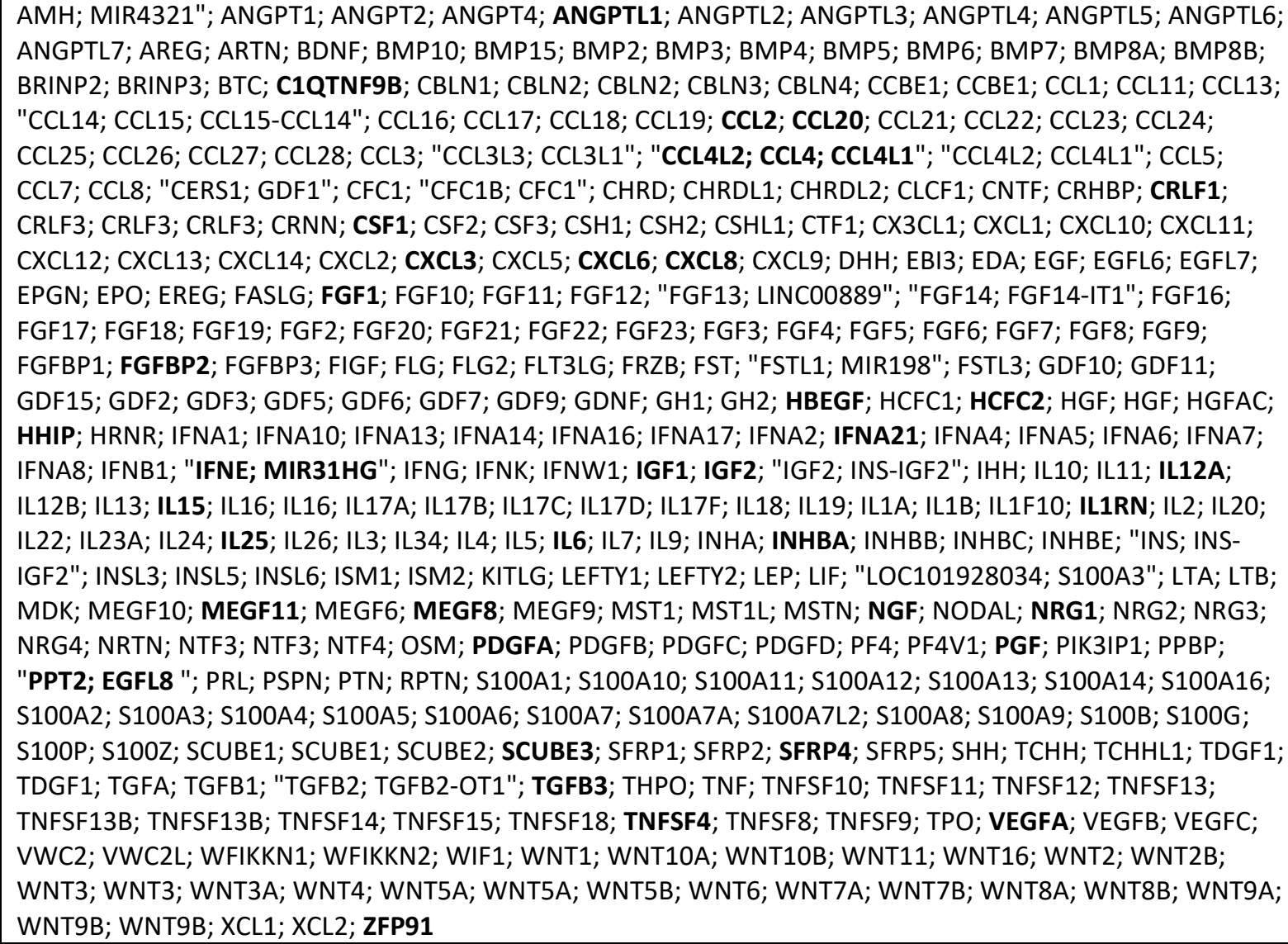 & $\begin{array}{l}\text { ANGPTL1 }(1,68) \\
\text { C1QTNF9B }(-1,65) \text { CCL2 } \\
(-2,12) \text { CCL20 }(1,69) \\
\text { "CCL4L2; CCL4L1" } \\
(1,58) \text { CLCF1 }(3,47) \\
\text { CRLF1 }(-2,89) \text { CXCL3 } \\
(1,65) \text { CXCL6 }(-2) \text { CXCL8 } \\
(2,7) \text { FGF1 }(-1,52) \\
\text { FGFBP2 }(-2,24) \text { HBEGF } \\
(1,55) \text { HCFC2 }(-1,99) \\
\text { HHIP }(2,94) \text { IFNA21 } \\
(1,64) \text { IFNE; MIR31HG (- } \\
\text { 3) IGF2 (-1,65) IL12A } \\
(1,67) \text { IL15 }(1,96) \text { IL1RN } \\
(3,05) \text { IL25 }(1,8) \text { IL6 } \\
(7,04) \text { INHBA }(2,2) \\
\text { MEGF11 }(-1,62) \text { MEGF8 } \\
(-1,61) \text { NGF }(6,2) \text { NRG1 } \\
(-1,58) \text { PDGFA }(1,91) \\
\text { PGF }(-1,63) \text { PPT2 }(2,13) \\
\text { SFRP4 }(-2,13) \text { TGFB3 (- } \\
1,58) \text { TNFSF4 }(1,58) \\
\text { VEGFA }(3,15) \text { ZFP91 (- } \\
1,59)\end{array}$ & $\begin{array}{l}\text { CLCF1 }(2,74) \text { CRLF1 (- } \\
1,84) \text { CSF1 }(1,88) \text { CXCL6 (- } \\
1,76) \text { CXCL8 }(2,43) \text { "IFNE; } \\
\text { MIR31HG" }(-2,6) \text { IGF1 (- } \\
1,59) \text { IL12A }(1,5) \text { IL6 } \\
(2,91) \text { INHBA }(2,22) \\
\text { MEGF8 }(-1,81) \text { NGF }(5,55) \\
\text { PDGFA }(2,32) \text { PPT2 }(1,68) \\
\text { SCUBE3 }(-3,65) \text { SFRP4 (- } \\
2,38) \text { TGFB3 }(-1,8) \\
\text { TNFSF4 }(1,85) \text { VEGFA } \\
(2,92)\end{array}$ \\
\hline
\end{tabular}


Figure S2. Mean FTIR-ATR spectra in the $\left[1450-950 \mathrm{~cm}^{-1}\right]$ range. Top (rich in cells) and bottom (rich in ECM) sides of dermal substitutes in control (Ctrl) condition, and $24 \mathrm{~h}$ and $48 \mathrm{~h}$ after long pulses (LP) and short pulses (SP) protocols.
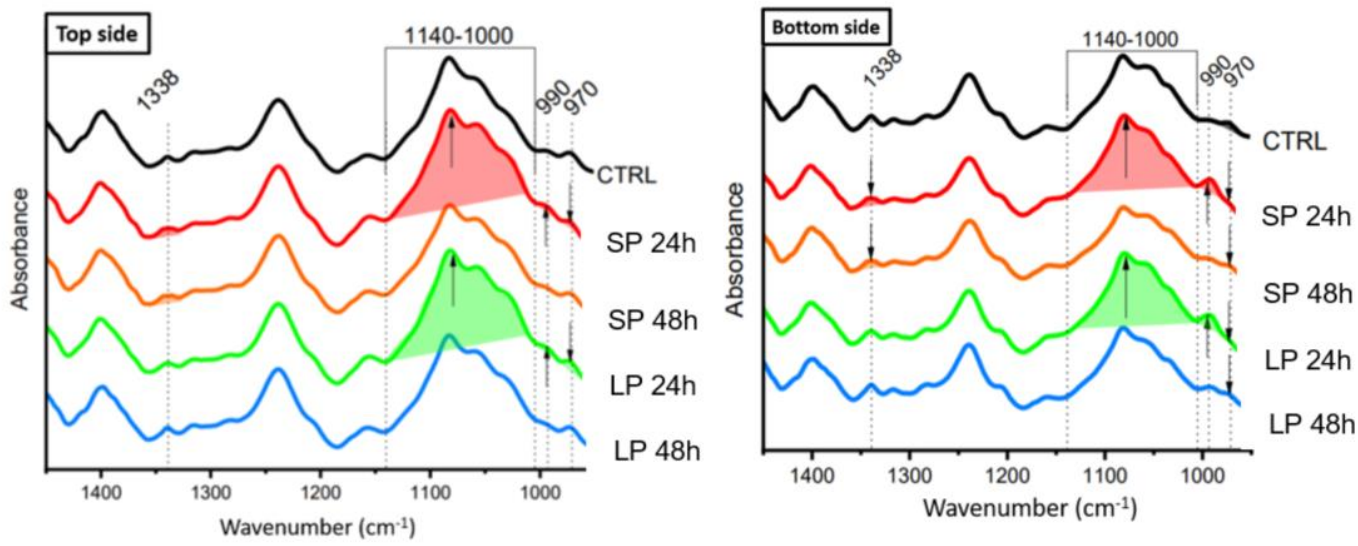

Figure S3. Modulation of (a) collagens and (b) matrix metalloproteinases (MMPs) family's mRNA $4 \mathrm{~h}$ after electrostimulation. Transcriptomic analyse using Clariom $\mathrm{S}$ Affymetrix array. $\mathrm{n}=4$. Long pulses (LP ): 10 pulses lasting $5 \mathrm{~ms}, 600 \mathrm{~V} / \mathrm{cm}$ at $1 \mathrm{~Hz}$ frequency; Short pulses (SP $\approx$ ): 8 pulses lasting $100 \mu \mathrm{s}, 1000 \mathrm{~V} / \mathrm{cm}$ at $1 \mathrm{~Hz}$ frequency.

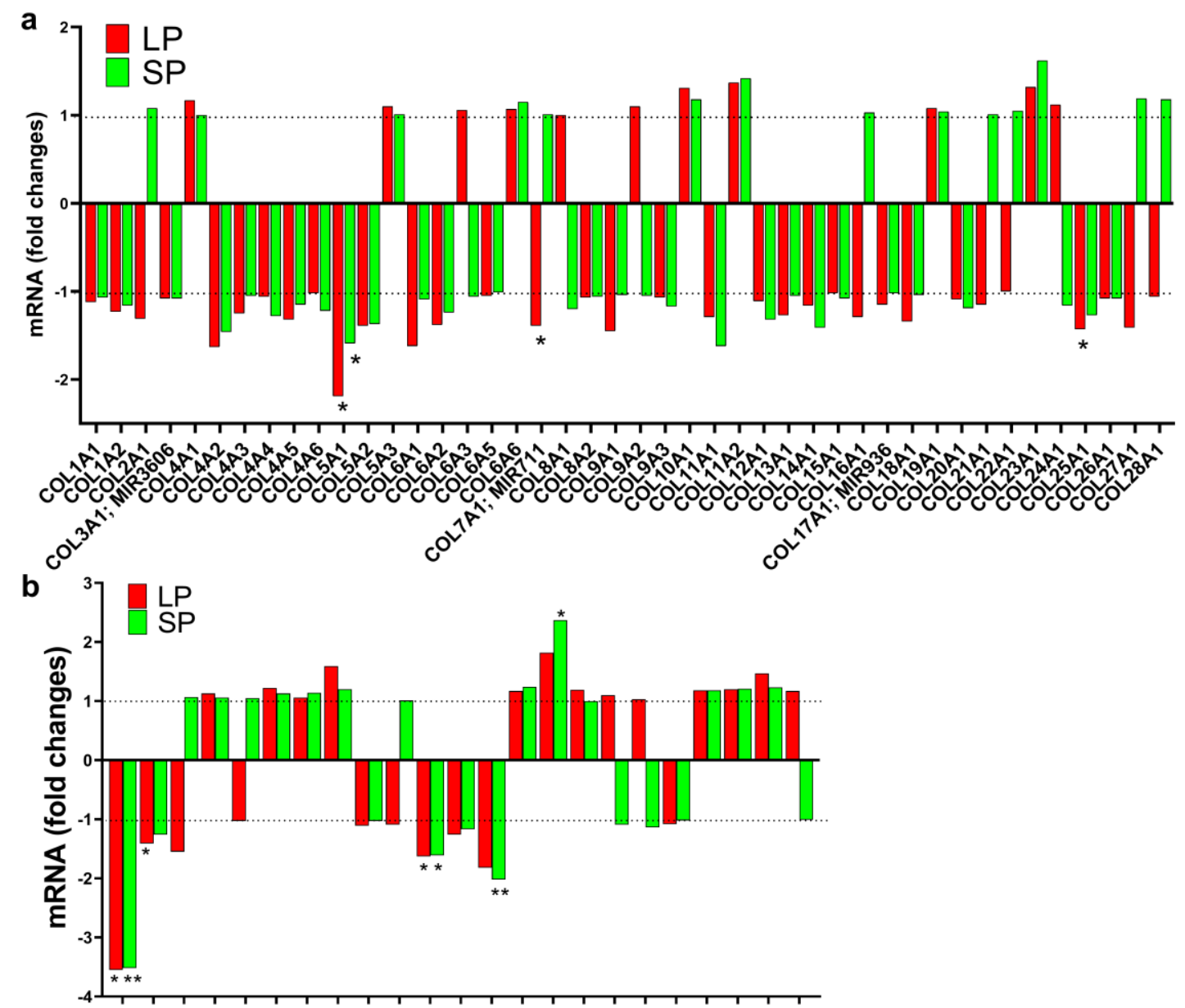


Supplementary text S4: DSC characterization of whole dermal substitutes after electrostimulation

Method. DSC measurements on hydrated dermal samples were performed with a DSC Pyris calorimeter (PERKIN ELMER, Waltham, MA) using an empty pan as reference. Samples (10-30 mg by mass) were sealed in hermetic aluminium pans and then submitted to a temperature program under helium atmosphere: a first cooling scan was performed from 20 to $-100{ }^{\circ} \mathrm{C}$ at $-10{ }^{\circ} \mathrm{C} \min ^{-1}$ followed by a heating scan from -100 to $85^{\circ} \mathrm{C}$ at $10{ }^{\circ} \mathrm{C} \mathrm{min}{ }^{-1}$. After completing the DSC measurements, pans were reweighted to check that they had been correctly sealed. The sample pans were pierced and dried to constant mass at $105^{\circ} \mathrm{C}$ for $14 \mathrm{~h}$ to determine the sample dry mass and by difference the total amount of water in defrosted samples.
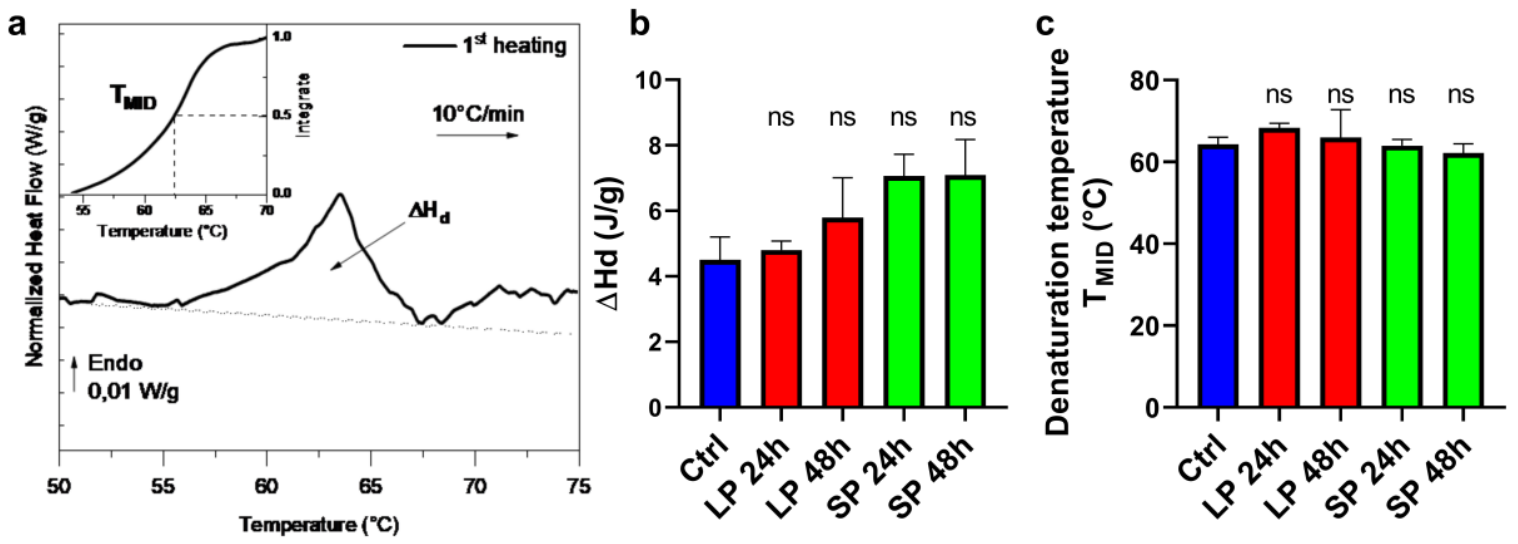

Figure S4. DSC analysis of dermal substitutes. a. Representative DSC curve of thermal denaturation of collagens in the $\left[50-75^{\circ} \mathrm{C}\right]$ window. b. Specific enthalpy of denaturation $\Delta \mathrm{H}_{\mathrm{d}}$ measured by DSC on the whole tissue. c. Determination of collagens integrity thanks to denaturation temperature $\mathrm{T}_{\mathrm{MID}}$.

Results. As previously observed in collagen-rich tissues (Badea et al, 2011; Samouillan et al, 2011; Tang et al, 2017), the endothermic phenomenon detected in the [55-70 ${ }^{\circ}$ range is attributed to the irreversible thermal denaturation of fibrillar collagens. This denaturation is a thermally activated process implying the rupture of hydrogen bonds coupling the three $\alpha$ chains and a rearrangement of the triple helix into a random chain configuration named gelatin. The denaturation is characterised by $\Delta H$, the area under the endotherm (Fig S4a). Once normalised to the dry mass, it gives a measure of the specific enthalpy of denaturation $\Delta H_{d}$. Despite a trend in increasing of the enthalpy of denaturation, no statistical difference was observed after electrostimulation (Fig S4b). Collagen's denaturation can be assessed using the denaturation temperature $\mathrm{T}_{\mathrm{MID}}$, corresponding to the temperature at which $50 \%$ of collagens is denatured, determined from the integral of the endotherm. Since $\mathrm{T}_{\mathrm{MID}}$ takes into account the distribution of the denaturation endotherm, it is a reliable indicator of collagen thermal stability. No significant difference was observed in $\mathrm{T}_{\mathrm{MID}}$ between control and electrostimulated conditions, indicating no variation in collagens integrity after external electric field applications (Fig S4c). 
a

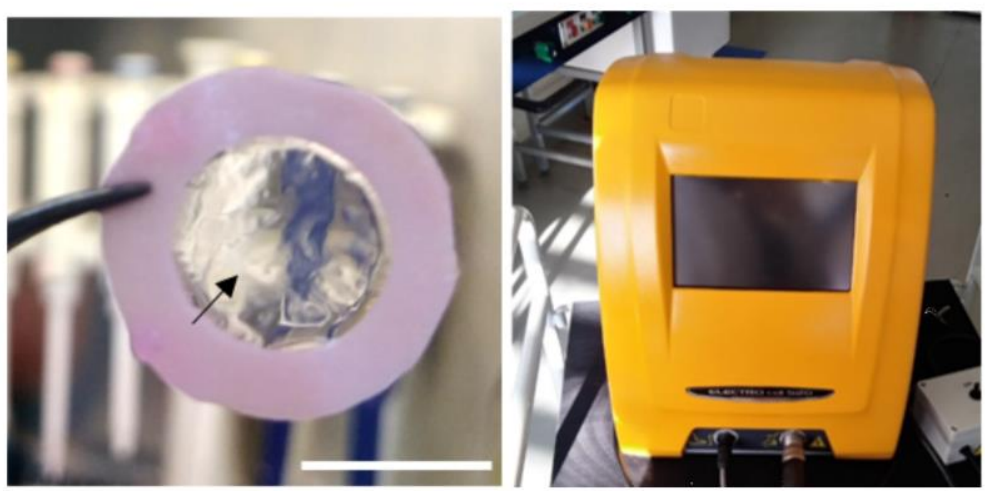

Long pulses (LP)
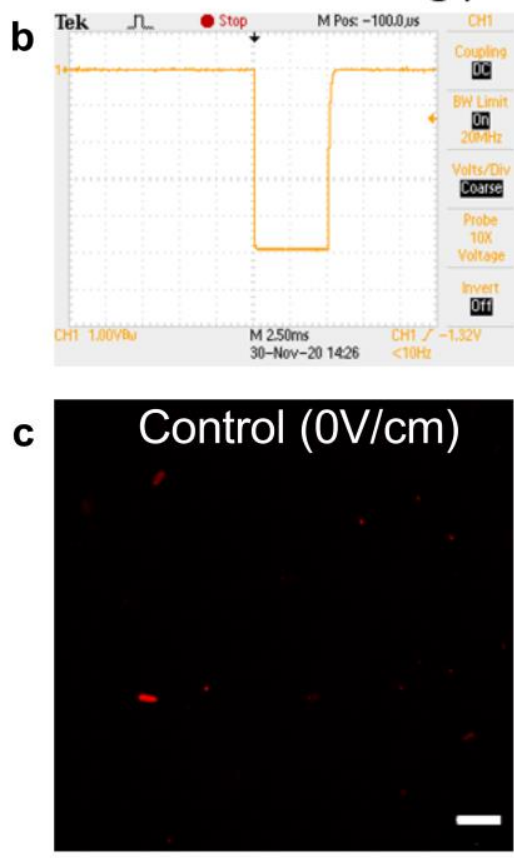

d

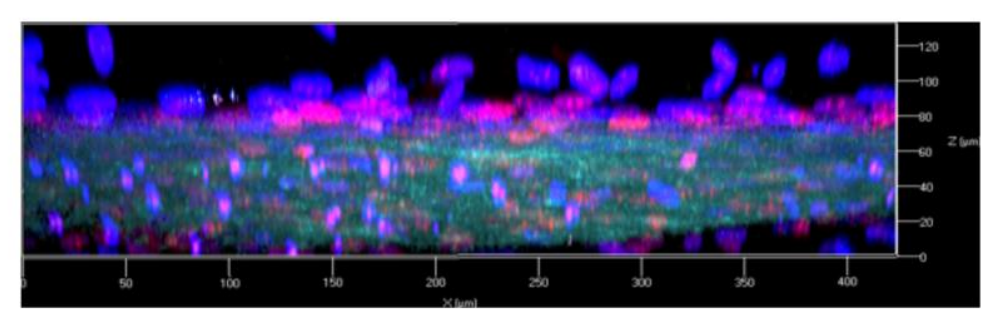

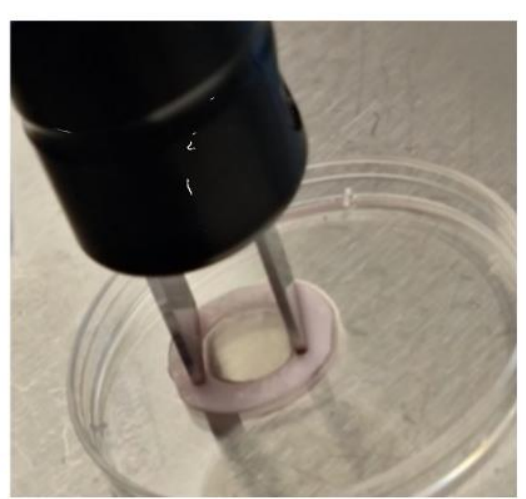

Short pulses (SP)
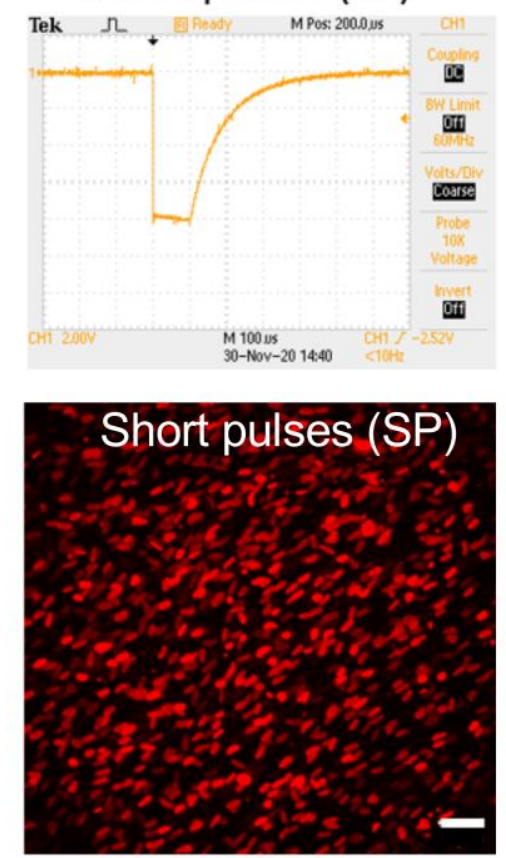

e

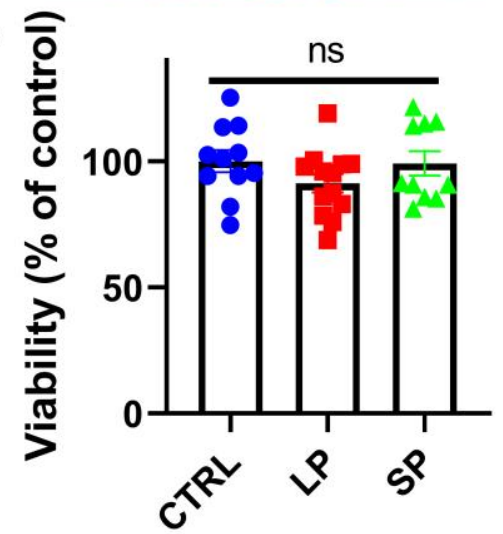

Figure S5. Long pulses (LP) and short pulses (SP) electric parameters induce transient and reversible fibroblasts electropermeabilization in human dermal substitute. a. Macroscopic aspect of dermal substitute (arrow), electropulsator and electrodes stimulating the whole substitute. b. Applied electric parameters profiles, extracted with an oscilloscope. Scale bar $=0.8 \mathrm{~cm}$. c. Plasma membrane integrity assessed with propidium iodide (red) penetration, observed by two-photon microscopy. Scale bar $=50 \mu \mathrm{m}$. d. Optical transversal section of SP electrostimulated dermal substitute observed by two-photon microscopy. Nuclei 
are labelled with Hoechst (blue), electropermeabilized cells with propidium iodide (pink) and collagens are observed by second harmonic generation (cyan). e. Cell viability determined with PrestoBlue assays $24 \mathrm{~h}$ after electric field applications $(n=12)$ indicates that these electrical parameters induce a reversible electroporation not leading to cell death. Data are represented as the mean value \pm SEM. ns: non-significant. Long pulses (LP): 10 pulses $5 \mathrm{~ms}$ long, $600 \mathrm{~V} / \mathrm{cm}$ at $1 \mathrm{~Hz}$ frequency; Short pulses (SP): 8 pulses $100 \mu \mathrm{s}$ long, $1000 \mathrm{~V} / \mathrm{cm}$ at $1 \mathrm{~Hz}$ frequency.

\section{Supplementary references}

Badea, E., Della Gatta, G. \& Budrugeac, P. Characterisation and evaluation of the environmental impact on historical parchments by differential scanning calorimetry. J. Therm. Anal. Calorim. 104, 495-506 (2011).

Belbachir, K., Noreen, R., Gouspillou, G. \& Petibois, C. Collagen types analysis and differentiation by FTIR spectroscopy. Anal. Bioanal. Chem. 395, 829-837 (2009).

Samouillan, V. et al. The Use of Thermal Techniques for the Characterization and Selection of Natural Biomaterials. J. Funct. Biomater. 2, 230-248 (2011).

Sanden, K. W. et al. The use of Fourier-transform infrared spectroscopy to characterize connective tissue components in skeletal muscle of Atlantic cod (Gadus morhua L.). J. Biophotonics 1-9 (2019) doi:10.1002/jbio.201800436.

Tang, R. et al. Identification of ageing biomarkers in human dermis biopsies by thermal analysis (DSC) combined with Fourier transform infrared spectroscopy (FTIR/ATR). Skin Res. Technol. 23, 573-580 (2017).

Wood, B. R. The importance of hydration and DNA conformation in interpreting infrared spectra of cells and tissues. 45, 1980-1998 (2016). 